\title{
Real-World Analysis of Survival and Clinical Events in a Cohort of Italian Perinatally HIV-1 Infected Children From 2001 to 2018
}

\section{OPEN ACCESS}

Edited by:

Dimitri Van der Linden, Cliniques Universitaires

Saint-Luc, Belgium

Reviewed by:

Jack Levy,

Université libre de Bruxelles, Belgium Mario M. D'Elios,

University of Florence, Italy

*Correspondence: Elena Chiappini

elena.chiappini@unifi.it

tThese authors have contributed equally to this work

Specialty section:

This article was submitted to Pediatric Infectious Diseases,

a section of the journal

Frontiers in Pediatrics

Received: 08 February 2021 Accepted: 15 June 2021 Published: 16 July 2021

Citation:

Chiappini E, Larotonda F, Lisi C Giacomet V, Erba P, Bernardi S, Zangari P, Di Biagio A, Taramasso L, Giaquinto C, Rampon O, Gabiano C, Garazzino S, Tagliabue C, Esposito S, Bruzzese E, Badolato R, Zanaboni D,

Cellini M, Dedoni M, Mazza A,

Pession A, Giannini AM, Salvini F, Dodi I, Carloni I, Cazzato S, Tovo PA,

de Martino M and Galli L (2021) Real-World Analysis of Survival and Clinical Events in a Cohort of Italian Perinatally HIV-1 Infected Children From 2001 to 2018.

Front. Pediatr. 9:665764. doi: 10.3389/fped.2021.665764

\begin{abstract}
Elena Chiappini ${ }^{1,2 *}$, Francesca Larotonda ${ }^{1,2}$, Catiuscia Lisi ${ }^{1,2}$, Vania Giacomet ${ }^{3 \dagger}$, Paola $\mathrm{Erba}^{3+}$, Stefania Bernardi ${ }^{4+}$, Paola Zangari ${ }^{5+}$, Antonio Di Biagio ${ }^{6 \dagger}$, Lucia Taramasso ${ }^{67}$, Carlo Giaquinto ${ }^{7 \dagger}$, Osvalda Rampon ${ }^{7 t}$, Clara Gabiano ${ }^{8 t}$, Silvia Garazzino ${ }^{87}$, Claudia Tagliabue ${ }^{9 \dagger}$, Susanna Esposito ${ }^{10 \dagger}$, Eugenia Bruzzese ${ }^{11 \dagger}$, Raffaele Badolato ${ }^{12 \dagger}$, Domenico Zanaboni ${ }^{13+}$, Monica Cellini ${ }^{14 t}$, Maurizio Dedoni ${ }^{15 t}$, Antonio Mazza ${ }^{16 \dagger}$, Andrea Pession ${ }^{17 \dagger}$, Anna Maria Giannini ${ }^{187}$, Filippo Salvini ${ }^{19 \dagger}$, Icilio Dodi ${ }^{20 t}$, Ines Carloni ${ }^{21+}$, Salvatore Cazzato ${ }^{21 t}$, Pier Angelo Tovo ${ }^{8 \dagger}$, Maurizio de Martino ${ }^{1,2+}$ and Luisa Galli ${ }^{1,2}$ for the Italian Register for HIV Infection in Children
\end{abstract}

\begin{abstract}
${ }^{1}$ Paediatric Infectious Diseases Unit, Department of Health Sciences, Anna Meyer Children's Hospital, University of Florence, Florence, Italy, ${ }^{2}$ Department of Paediatric Medicine, Anna Meyer Children's Hospital, University of Florence, Florence, Italy, ${ }^{3}$ Paediatric Infectious Diseases Unit, Department of Paediatrics, Luigi Sacco Hospital, University of Milan, Milan, Italy, ${ }^{4}$ Unit of Immune and Infectious Diseases, Stefania Bernardi Academic Department of Pediatrics (DPUO), Bambino Gesù Children's Hospital, Istituti di Ricovero e Cura a Carattere Scientifico, Rome, Italy, ${ }^{5}$ Research Unit of Clinical Immunology and Vaccinology, Paola Zangari Academic Department of Pediatrics (DPUO), Bambino Gesù Children's Hospital, Istituti di Ricovero e Cura a Carattere Scientifico, Rome, Italy, ${ }^{6}$ Infectious Diseases Unit, Policlinico San Martino Hospital, University of Genova, Genoa, Italy, ${ }^{7}$ Department of Women and Child Health, University of Padova, Padua, Italy, ${ }^{8}$ Paediatric Infectious Diseases Unit, Regina Margherita Children's Hospital, University of Turin, Turin, Italy, ${ }^{9}$ Paediatric Highly Intensive Care Unit, Department of Pathophysiology and Transplantation, Istituti di Ricovero e Cura a Carattere Scientifico Ca' Granda Ospedale Maggiore Policlinico Foundation, University of Milan, Milan, Italy, ${ }^{10}$ Paediatric Department, Pietro Barilla Children's Hospital, University of Parma, Parma, Italy, ${ }^{11}$ Paediatric Unit, Department of Translational Medical Sciences, University of Naples Federico II, Naples, Italy, ${ }^{12}$ Department of Clinical and Experimental Sciences, University of Brescia, Brescia, Italy, ${ }^{13}$ Department on Internal Medicine and Therapeutics, Istituti di Ricovero e Cura a Carattere Scientifico Policlinico "S. Matteo" Foundation, University of Pavia, Pavia, Italy, ${ }^{14}$ Paediatric Hemato-Oncology Unit, Department of Medical and Surgical Sciences, University of Modena and Reggio Emilia, Modena, Italy, ${ }^{15}$ Department of Paediatrics, Ospedale Microcitemico, Cagliari, Italy, ${ }^{16}$ Department of Paediatrics, "S. Chiara" Hospital, Trento, Italy, ${ }^{17}$ Paediatric Unit, IRCCS Scientific Institute for Research and Healthcare, Sant'Orsola Hospital, Bologna, Italy, ${ }^{18}$ Paediatric Infectious Diseases Unit, University Hospital Policlinico Giovanni XXIII, Bari, Italy, ${ }^{19}$ Department of Paediatrics, Niguarda Hospital, University of Milan, Milan, Italy, ${ }^{20}$ Department of Medicine and Surgery, Pietro Barilla Children's Hospital, University of Parma, Parma, Italy, ${ }^{21}$ Department of Mother and Child Health, Salesi Children's Hospital, Ancona, Italy
\end{abstract}

Background: Combined antiretroviral therapy (CART) has been associated with a steep decrease in mortality and morbidity in HIV-1 infected children. New antiretroviral molecules and drug classes have been developed and the management of HIV-infected children has improved, but recent data on survival are limited.

Methods: An observational retrospective study investigating changes in mortality and morbidity was conducted on 1,091 perinatally HIV-1 infected children enrolled in the Italian Register for HIV Infection in Children and followed-up from 2001 to 2018.

Results: Three hundred and fifty-four (32\%) AIDS events and 26 (2\%) deaths occurred overtime. Mortality rates decreased from 0.4/100 person-years in 2001-2006 to $0.27 / 100$ person-years in 2007-2012 and 0.07/100 person-years in 2013-2018. Notably, $92 \%$ of the dead children were born in Italy, but only $50 \%$ were followed-up since birth or within three months of age. Seventy three percent of children had 
started CART at age $\geq 6$ months; $23 \%$ were treated for $<30$ days before death. B and $\mathrm{C}$ clinical events progressively decreased $(P<0.0001)$. Opportunistic infections significantly decreased over time, but still were the most common events in all the periods (6.76/100 person-years in 2013-2018). In the last period, severe bacterial infections were the most common ones. Cancer rates were 0.07/100; 0.17/100; 0.07/100 person-years in the three periods, respectively.

Conclusions: Progressive reductions both in mortality and in rates of class $\mathrm{B}$ and $\mathrm{C}$ clinical events and Ols have been observed during the CART era. However, deaths were still registered; more than half of dead children were enrolled after birth and had belatedly started cART.

Keywords: HIV, perinatal infection, children, antiretroviral therapy (ART), aids, survival, epidemiology

\section{INTRODUCTION}

The cART was introduced in 1996 and, thanks to the use of different agents targeting various steps of the HIV life cycle, had a material impact on the HIV infection pandemic (1). From 1996 to nowadays, numerous aspects regarding the treatment of the HIV infected paediatric population changed. New antiretroviral drug classes have been introduced (such as integrase inhibitors) $(2,3)$; the proportion of children receiving cART increased and the time of exposure to cART is extending $(4,5)$; several paediatric 2-in-1 and 3-in-1 fixed-dose combinations (FDC) have become available and have received quality certification by the WHO and FDA for use in children; the development of paediatric antiretroviral drugs and formulations has been prioritised by WHO, which published a paediatric drug development toolkit summarising the challenges and solutions for promoting and accelerating development of antiretroviral formulations suitable for infants, children, and adolescents $(6,7)$. Mortality rates and rates of hospitalisation and progression to AIDS dramatically decreased from the pre-cART era to the cART era, in parallel with better viral suppression and higher $\mathrm{CD} 4^{+} \mathrm{T}$-cells counts (8-10). In particular, the prognosis of HIV-1 infected children has considerably improved thanks to early treatment with cART (11). It has been demonstrated that early HIV diagnosis and early initiation of antiretroviral therapy reduce infant mortality by $76 \%$ and HIV progression by $75 \%$ (12). The benefit of treating HIV-infected infants early in life has been quantified in a large population of 210 infants from 11 European countries: the risk of developing AIDS or death at 1 year was $1.6 \%$ in infants treated before 3 months of life and $11.7 \%$ in infants treated later $(P<0.001)(11)$. Initiating cART as soon as possible after birth (in particular before the age of 5 months) has also been related to a better recovery of CD4+ cell count $(13,14)$.

However, non-AIDS related deaths (associated to metabolic complications, drug induced adverse events or organ failures) are emerging and their number is increasing (15-17). From 1996 onward, incidence rates of opportunistic infections (OIs) decreased, especially central nervous system infections, candidiasis, lymphoid interstitial pneumonia, Pneumocystis jirovecii pneumonia, and disseminated TB (18-21). Incidence rates of HIV associated nephropathy (HIVAN) and HIV encephalopathy (HIVE) significantly decreased, too (22-25). However, new aspects are emerging: in the low-to-middle income countries (LMICs) the incidence of bacterial pneumonia, tuberculosis, candidiasis and varicella remained stable over years despite the use of cART (26) and chronic lung disease is emerging among older children and adolescents (27); other types of renal disease (i.e., tubular dysfunction, human immunodeficiency virus immune complex kidney disease, urinary tract infections) (28-30) and milder neurocognitive deficits (i.e., lower total intelligence quotient, language impairment, poorer working memory) (31-37) are occurring always more frequently. Cancer rates considerably decreased after year 2000, when the cART use was widely diffused (38-40). The incidence rates of AIDS-defining cancers have been deeply reduced during the cART era but non-AIDS-defining cancers (such as Hodgkin lymphoma, leiomyosarcoma and other sarcomas, hepatocarcinoma) surprisingly increased (41-43). Incidence rates of malignancies in HIV-infected children are, still today, much higher than those in the healthy paediatric population (44).

Monitoring the variations of HIV associated symptoms and signs, collecting relevant clinical events and laboratory information, understanding the new aspects of the disease is extremely important to investigate the impact of cART on the HIV infected paediatric population and to improve children's quality of life and life expectancy. An observational population study was previously conducted (19) on perinatally HIV-1 infected children enrolled in the Italian Register for HIV Infection in Children from 1985 to 2005, analysing survival rates and CDC class $\mathrm{B}$ and $\mathrm{C}$ clinical events during the pre-cART and cART eras. Progressive reduction in mortality rates and clinical events was reported, while the occurrence of OIs (particularly severe bacterial infections and pneumonia) still was at higher rates. The purpose of this study is to continue investigating how clinical events among HIV-infected children are changing in the most recent years.

\section{MATERIALS AND METHODS Study Design}

An observational population study was conducted on perinatally HIV-1 infected children enrolled in the Italian Register for HIV 


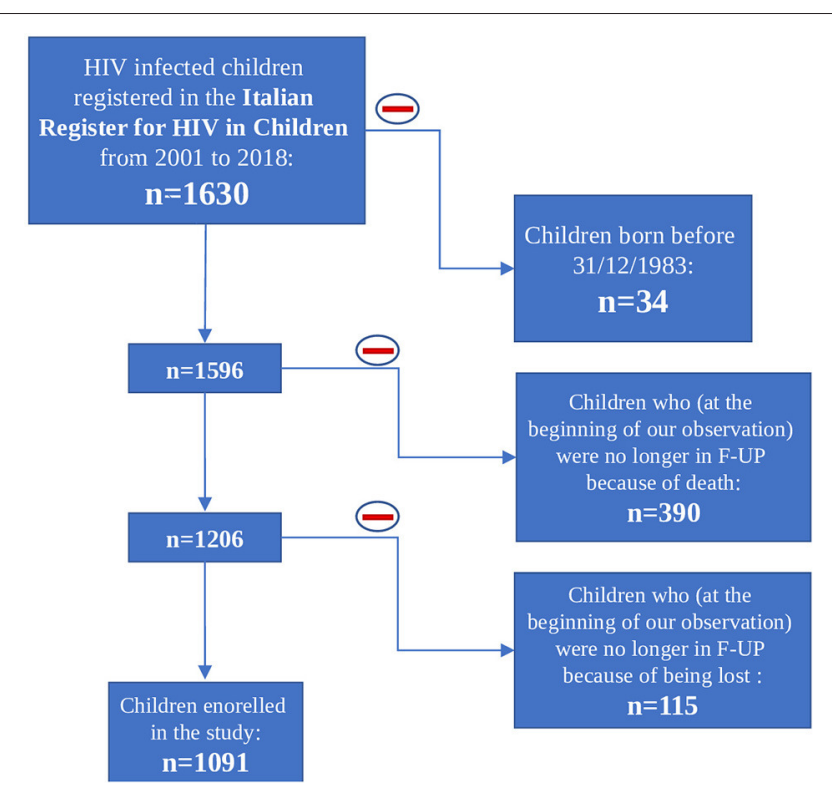

FIGURE 1 | Children included and excluded from the study population.

Infection in Children from 2001 to 2018. Data from children prospectively followed from birth were analysed separately. Children lost to follow-up were censored at last cheque. The rates of CDC class B and C clinical events, including malignancies, organ-specific complications and OIs, were analysed. Incidence rates of deaths and clinical events were compared to data collected from 1985 to 2005 in the Italian Register for HIV Infection in Children and published on AIDS Journal in 2007 (19).

\section{Data Collection}

Data were collected by the Italian Register for HIV Infection in Children, which is a nationwide multicentre study of children exposed to HIV-1 instituted in 1985 by the Italian Society of Paediatrics. The data source is a network of 106 paediatric clinics distributed throughout Italy, and it has been proved to be highly representative $(86.5 \%)$ of the entire Italian population of HIV-1-infected children (9). The data are transmitted to the two coordinating centres, the Departments of Paediatrics in the Universities of Florence and Turin. In this study data collected from all perinatally infected children never lost to follow-up up to December 31, 2018 were analysed.

\section{Laboratory Investigations}

$\mathrm{CD}^{+}$T-lymphocytes and HIV-RNA viral loads (VL) were measured by each Italian centre involved in the study with standardised methods. According to the US guidelines for the use of antiretroviral agents in paediatric HIV-1 infection, $\mathrm{CD}^{+}{ }^{+}$T-cell percentages, rather than their absolute counts, were utilised, as these percentages reflect the immune status of HIV-1-infected children more accurately.

\section{Treatment}

The specific therapy offered was based upon decision criteria proposed by the Italian and US guidelines $(15,16)$. The cART was defined as a combined antiretroviral therapy consisting of at least three antiretroviral drugs of two different classes (e.g., protease inhibitors, nucleoside reverse transcriptase inhibitors, non-nucleoside reverse transcriptase inhibitors, and integrase inhibitors). Moreover, several two-drugs based regimens were considered as cART (i.e., darunavir/cobicistat or darunavir/ritonavirraltegravir; darunavir/cobicistat or darunavir/ritonavirdolutegravir; lamivudine-darunavir/cobicistat; lamivudinedarunavir/ritonavir). Dual therapy regimens with lamivudine and dolutegravir have been included.

\section{Calendar Periods}

Clinical event rates were analysed starting from 2001 to 2018. This time was subdivided into three periods: from 2001 to 2006, from 2007 to 2012 and from 2013 to 2018, each one six-year-long.

\section{Definitions}

Clinical events were diagnosed, at each participating centre, by a paediatrician and infectious diseases specialist, expert in HIV-1 infection. The diagnoses were based on the 1994 CDC classification and definitions (17), as follows: AIDS was defined as the first-class $\mathrm{C}$ event according to the CDC's definition; class $\mathrm{B}$, and C clinical events and HIV-1related organ-specific complications (i.e., lymphoid interstitial pneumonia, HIV-1-related encephalopathy, cardiomyopathy, hepatopathy, nephropathy) were strictly defined according to the recommendations laid down by the CDC. All the clinical events that did not fit CDC definitions, were reported as "non-AIDS related" events. Haematological alterations (HIV1-related anaemia, granulocytopenia, and thrombocytopenia) were evaluated in total. Malignancies included all cancers developed during the observation time. Both AIDS-defining cancers (brain lymphomas, small non-cleaved cell nonHodgkin lymphoma, immunoblastic or large-cell lymphoma of B cell or unknown immunological phenotype and Kaposi sarcoma) and other cancers (i.e., leiomyosarcoma, cervical carcinoma, hepatoblastoma, or acute lymphoblastic leukaemia) were considered. OIs included candidiasis (considering separately as persistent/recurrent oral or skin candidiasis and oesophageal/tracheobronchial disease), cytomegalovirusrelated disease (cytomegalovirus retinitis and all other forms of cytomegalovirus disease other than retinitis, excluding congenital cytomegalovirus infection), cryptosporidiosis, polydermatomeric herpes zoster, disseminated herpes simplex, Pneumocystis jirovecii pneumonia, systemic fungal infection (cryptococcosis, coccidioidomycosis, histoplasmosis), progressive multifocal leukoencephalopathy, disseminated Mycobacterium avium complex, and serious bacterial infections. The last included bacteraemia, internal organ abscess, meningitis, osteomyelitis, ascertained or presumptive bacterial pneumonia, septic arthritis, pyelonephritis, and mastoiditis. 


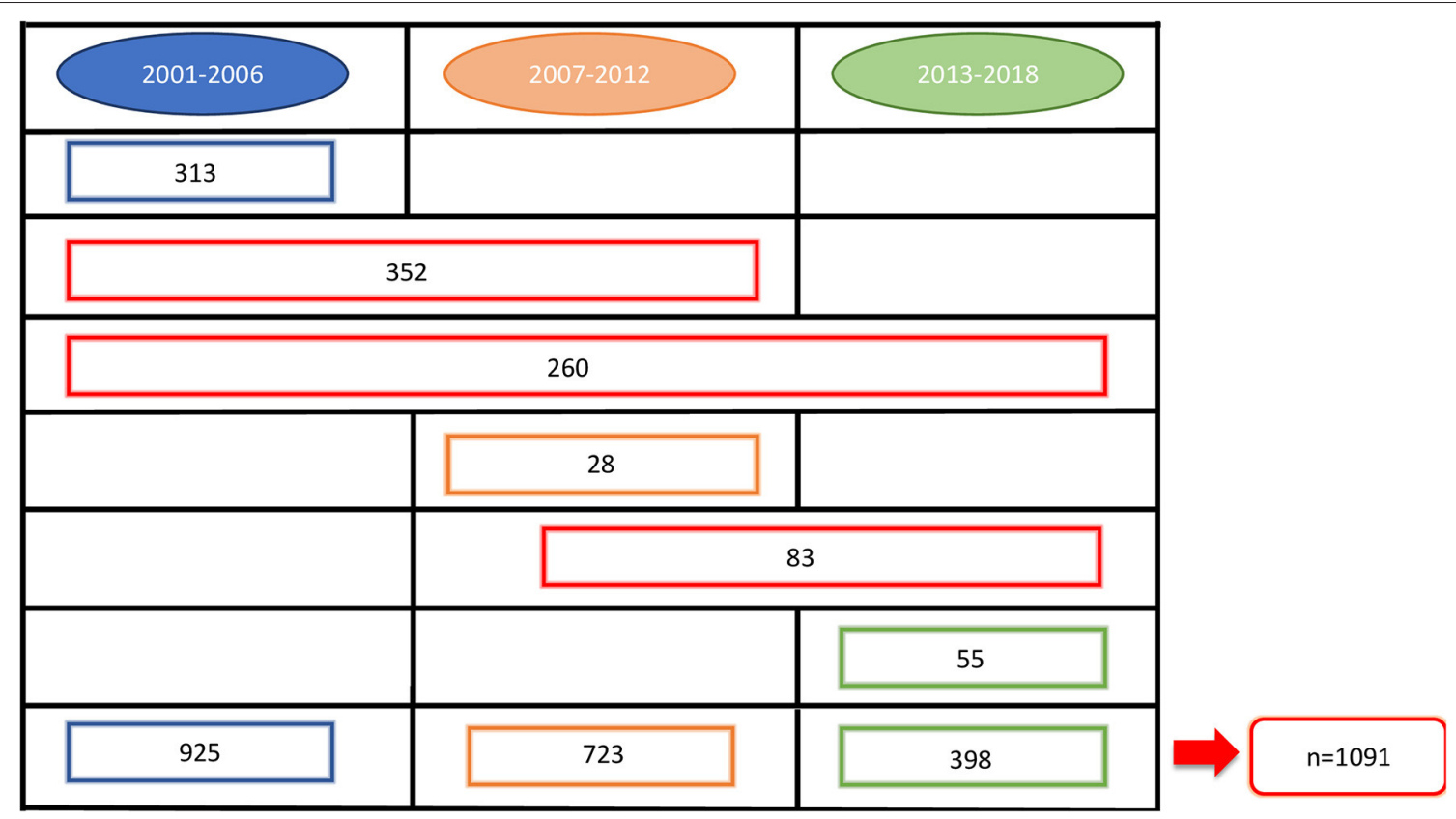

FIGURE 2 | Number of children who contributed to the three periods of analysis.

TABLE 1 | Characteristics of the 1,091 HIV-1 infected children, by calendar period of observation.

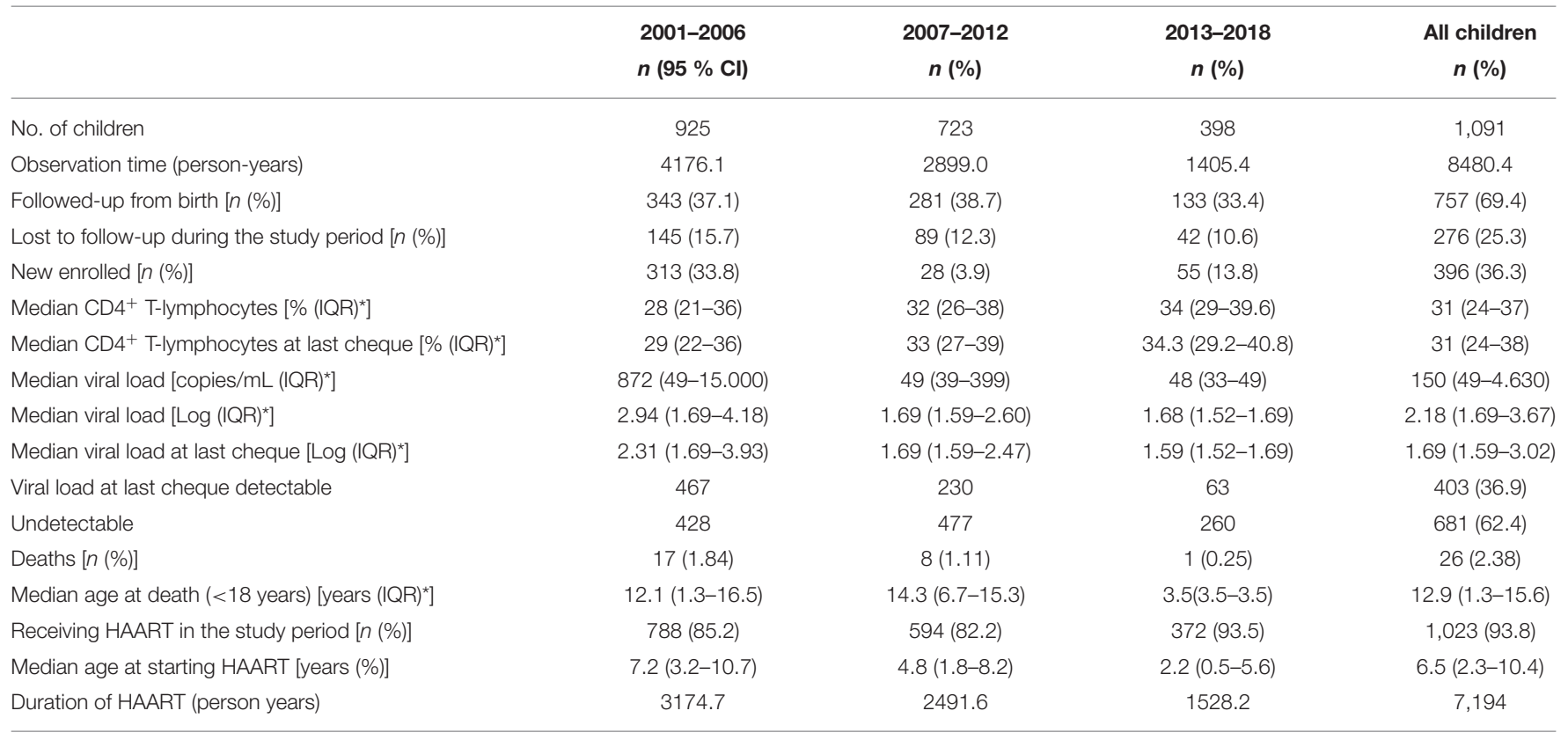

${ }^{*} I Q R$, interquartile range.

\section{Statistical Analysis}

Age, VL, and $\mathrm{CD} 4^{+}$T-lymphocyte percentage were expressed as the median and interquartile range (IQR). VL data were provided by the centres belonging to the Italian Register for HIV Infection in Children. The cut-off for undetectable VL was different in the various laboratories and varied over time. In particular, VL was defined undetectable when $<400$ copies $/ \mathrm{mL}$ in $3 \%$ of undetectable cases, $\mathrm{VL}<80$ copies $/ \mathrm{mL}$ in $0.15 \%, \mathrm{VL}$ $<50$ copies $/ \mathrm{mL}$ in $51 \%$, VL $<40$ copies $/ \mathrm{mL}$ in $17 \%, \mathrm{VL}<$ 37 copies $/ \mathrm{mL}$ in $10 \%, \mathrm{VL}<34$ copies $/ \mathrm{mL}$ in $5 \%, \mathrm{VL}<20$ copies $/ \mathrm{mL}$ in $12 \%, \mathrm{VL}<3$ copies $/ \mathrm{mL}$ in $2 \%$. Viremia was assessed considering the most recent viremia within 6 months. Clinical events were assigned to the period during which they occurred and the number of events per 100 person-years of observation 
TABLE 2 | Mortality rates among the study periods adjusted for age.

\begin{tabular}{|c|c|c|c|c|c|c|}
\hline Factors & Events $(n)$ & Person-years & Univariate IRR* $\left(95 \% \mathrm{Cl}^{\star}\right)$ & $\boldsymbol{P}$ & Multivariate IRR* $\left(95 \% \mathrm{CI}^{\star}\right)$ & $\boldsymbol{P}$ \\
\hline \multicolumn{7}{|l|}{ Period } \\
\hline 2001-2006 & 17 & 4176.1 & 1 & & 1 & \\
\hline 2007-2012 & 8 & 2899.0 & $0.71(0.26-1.89)$ & 0.489 & $0.97(0.23-4.10)$ & 0.971 \\
\hline 2013-2018 & 1 & 1405.4 & $0.06(0.01-0.43)$ & 0.006 & $0.07(0.01-0.64)$ & 0.019 \\
\hline \multicolumn{7}{|l|}{ Sex } \\
\hline \multicolumn{7}{|l|}{ Follow-up } \\
\hline From birth & 8 & 3365.4 & 1 & & & \\
\hline After birth & 18 & 5115.0 & $1.36(0.51-3.65)$ & 0.536 & & \\
\hline \multicolumn{7}{|l|}{ Place of birth } \\
\hline Italy & 24 & 7026.4 & 1 & & & \\
\hline Detectable & 15 & 1854.4 & $6.45(1.38-30.11)$ & 0.018 & $2.08(0.40-10.95)$ & 0.387 \\
\hline Missing & 9 & 3582.7 & $2.54(0.54-12.01)$ & 0.241 & $1.22(0.23-6.51)$ & 0.818 \\
\hline \multicolumn{7}{|c|}{ CD4+ T-lymphocyte percentage at the last cheque } \\
\hline $15 \%$ & 13 & 336.0 & 1 & & 1 & \\
\hline$>15 \%$ & 4 & 4434.8 & $0.02(0.003-0.08)$ & $<0.0001$ & $0.03(0.01-0.11)$ & $<0.0001$ \\
\hline Missing & 9 & 3709.6 & $0.08(0.03-0.22)$ & $<0.0001$ & $0.19(0.03-1.32)$ & 0.093 \\
\hline \multicolumn{7}{|l|}{ Date of birth } \\
\hline After 1996 & 16 & 4611.8 & 1 & & & \\
\hline Before 1996 & 10 & 3868.6 & $1.31(0.52-3.32)$ & 0.565 & & \\
\hline
\end{tabular}

*IRR, incidence rate ratio; Cl, confidence interval.

time in the corresponding period was calculated. Event rates were reported as rates per 100 person-years and 95\% confidence intervals (CI) were calculated. Additionally, the incidence rate ratio (IRR) was calculated. A single patient could contribute to multiple events (except for the mortality analysis) to the same or different periods; consequently, a Poisson regression model, adjusted for age and correlated observation across time within the same patient, was used to compare morbidity rates among the study periods. Therefore, the adjusted rate ratio (RR) was calculated. To test the influence of co-variables and to identify factors associated with OIs or cancer, a multivariate analysis was performed using the Poisson regression model, as indicated by the dichotomous nature of the dependent variable. For insertion into the model, only variables with a critical value of $P<0.05$ were considered. Statistical analyses were performed using STATA/SE, version 13.0 (Stata Corporation, College Station, Texas, USA). $P<0.05$ was considered statistically significant.

\section{RESULTS}

\section{Study Population}

At the beginning of our observation, in 2001, 1,630 perinatally HIV-1 infected children were enrolled in the Italian Register for HIV Infection in Children. We excluded from our study population all the children born before 31/12/1983 $(n=34)$ because they already were over 18 years old. Moreover, 505 children were excluded because no longer in follow up from 2001 onwards: 390 because of death and 115 because lost to follow up. The remaining 1,091 HIV-1 infected children were enrolled in our study. Among these 1,091 children, 276 (25.3\%) were lost to follow up, $77(7.1 \%)$ of whom were followed up from birth (Figure 1). Nine hundred thirty-five children were part of the first study period, 723 of the second one and 398 of the third one. Three hundred ninety-six children contributed to only one period of analysis, 435 children to two periods and 260 children to three periods (Figure 2). Three hundred forty-three $(37.1 \%)$ children belonging to the first study period were followed up from birth, 281 (38.7\%) children were in follow up from birth during the second period and 133 (33.4\%) during the third one (Table 1). Seven hundred twenty-seven children were already in the Italian Register for HIV Infection in Children before 2001. New enrolments during the whole study period (2001-2018) were 396: 313 in the first period, 28 in the second one and 55 in the third one (Table 1). All the data regarding children over 18 years old were excluded from the analysis, in order to specifically characterise paediatric population. Each child contributed to the study for 7.5 years (median; IQR: 3.7-11.2) and total observation time was 8480.4 years. Overall, 26 (2.4\%) children died during the study period. The characteristics of our study population are summarised in Table 1. 
TABLE 3 | Characteristics of deaths in perinatally HIV-1 infected children (from 2001 to 2018).

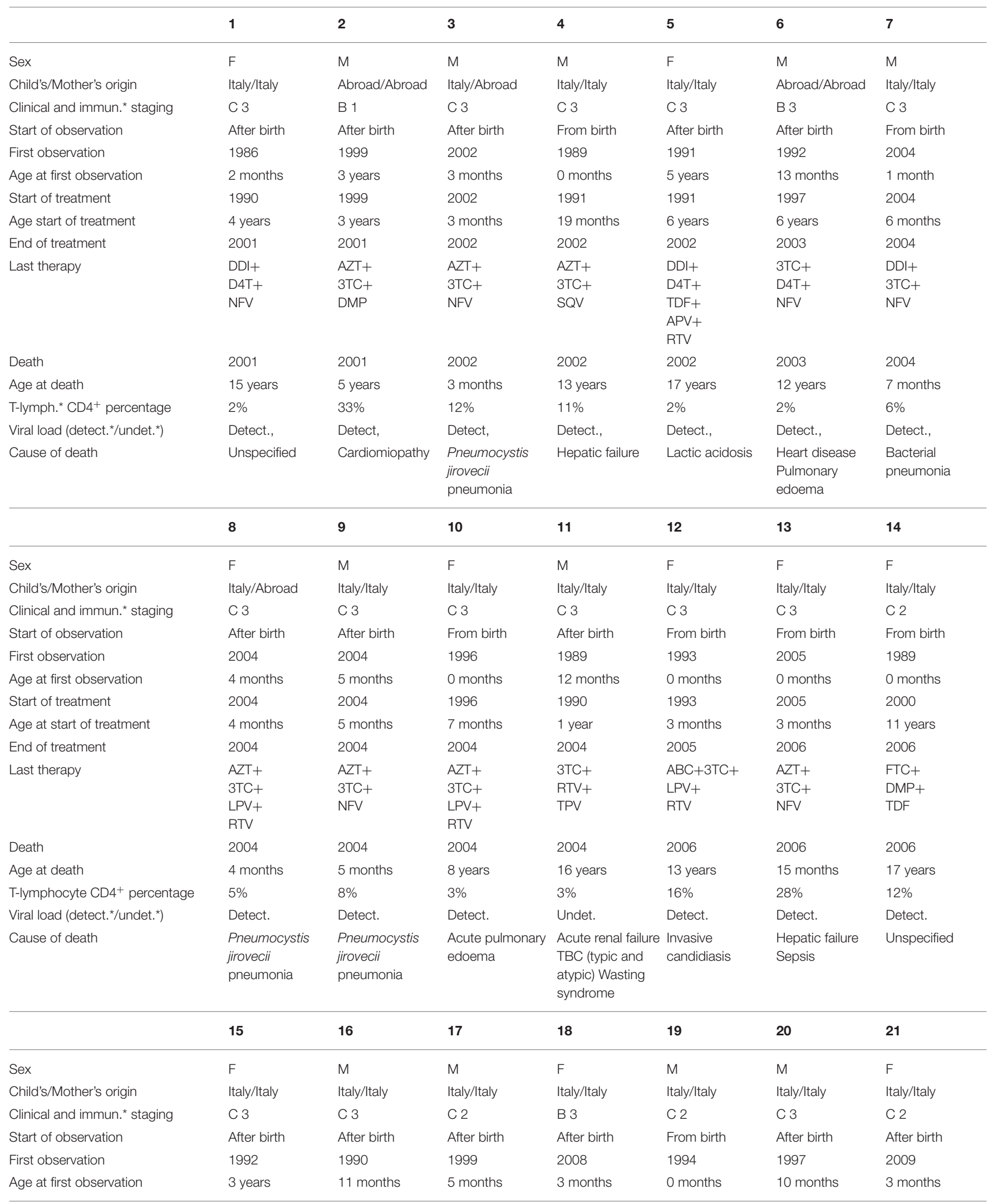


TABLE 3 | Continued

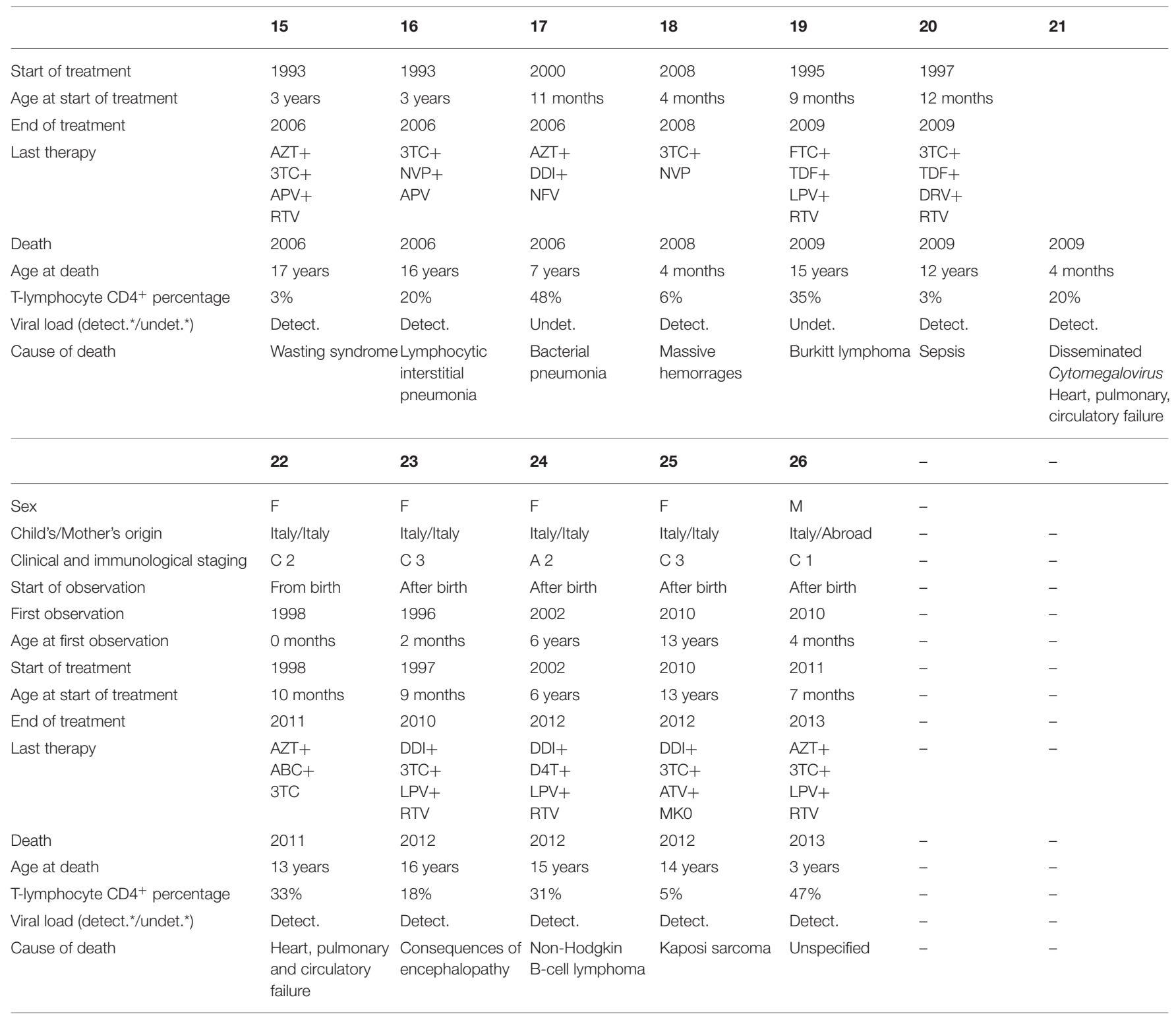

*Immun., immunological; lymph, lymphocyte; detect., detectable; undet., undetectable.

TABLE 4 | Centres for disease control and prevention class B and C clinical events in HIV-1 infected children by calendar period.

\begin{tabular}{|c|c|c|c|c|c|}
\hline Event class and calendar period & Events $(n)$ & Person-years & Rate ratio (events/100 person-years) & Adjusted $^{\mathrm{a}} \mathbf{R R}^{\star}\left(95 \% \mathrm{Cl}^{\star}\right)$ & $P$ \\
\hline \multicolumn{6}{|l|}{ Class B } \\
\hline 2001-2006 & 180 & 4176.1 & 4.31 & 1 & \\
\hline 2007-2012 & 92 & 2899.0 & 3.17 & $0.53(0.36-0.79)$ & 0.002 \\
\hline 2013-2018 & 25 & 1405.4 & 1.78 & $0.19(0.11-0.37)$ & $<0.0001$ \\
\hline \multicolumn{6}{|l|}{ Class C } \\
\hline 2013-2018 & 42 & 1405.4 & 2.99 & $0.31(0.18-0.53)$ & $<0.0001$ \\
\hline
\end{tabular}

${ }^{\star} R R$, rate ratio; $\mathrm{Cl}$, confidence interval.

${ }^{a}$ Adjusted for age and repeated events in the same patients. 
TABLE 5 | Class B and C event rates among the study periods adjusted for age.

\begin{tabular}{|c|c|c|c|c|c|c|}
\hline Factors & Events (n) & Person-years & Univariate IRR* $\left(95 \% \mathrm{Cl}^{\star}\right)$ & $P$ & Multivariate IRR* $\left(95 \% \mathrm{Cl}^{\star}\right)$ & $P$ \\
\hline \multicolumn{7}{|l|}{ CLASS B } \\
\hline \multicolumn{7}{|l|}{ Period } \\
\hline 2001-2006 & 180 & 4176.1 & 1 & & 1 & \\
\hline 2007-2012 & 92 & 2899.0 & $0.53(0.36-0.79)$ & 0.002 & $0.53(0.36-0.79)$ & 0.002 \\
\hline 2013-2018 & 25 & 1405.4 & $0.20(0.11-0.37)$ & $<0.0001$ & $0.19(0.10-0.35)$ & $<0.0001$ \\
\hline \multicolumn{7}{|l|}{ Follow-up } \\
\hline From & 81 & 3365.4 & 1 & & & \\
\hline After birth & 216 & 5115.0 & $1.78(1.23-2.57)$ & 0.002 & 1.86 (1.29-2.68) & 0.001 \\
\hline \multicolumn{7}{|l|}{ Date of birth } \\
\hline After 1996 & 908 & 4611.8 & 1 & & & \\
\hline Before 1996 & 89 & 3868.6 & $0.94(0.65-1.36)$ & 0.746 & & \\
\hline \multicolumn{7}{|l|}{ CLASS C } \\
\hline \multicolumn{7}{|l|}{ Period } \\
\hline 2001-2006 & 229 & 4176.1 & 1 & & 1 & \\
\hline 2007-2012 & 83 & 2899.0 & 0.47 (0.32-0.69) & $<0.0001$ & 0.47 (0.32-0.68) & $<0.0001$ \\
\hline 2013-2018 & 42 & 1405.4 & $0.31(0.18-0.53)$ & $<0.0001$ & $0.29(0.17-0.49)$ & $<0.0001$ \\
\hline \multicolumn{7}{|l|}{ Follow-up } \\
\hline From & 74 & 3365.4 & 1 & & & \\
\hline After birth & 280 & 5115.0 & $2.44(1.66-3.60)$ & $<0.0001$ & $2.54(1.74-3.71)$ & $<0.0001$ \\
\hline \multicolumn{7}{|l|}{ Date of birth } \\
\hline After 1996 & 225 & 4611.8 & 1 & & & \\
\hline Before 1996 & 129 & 3868.6 & $1.19(0.87-1.61)$ & 0.275 & & \\
\hline
\end{tabular}

${ }^{\star} \mathrm{Cl}$, confidence interval.

\section{Analysis of Survival}

Among the 1,091 children, 925 patients were observed in the period 2001-2006; 723 in 2007-2012; and 398 in 20132018. Within the same periods, 17,8 , and 1 deaths occurred, respectively, with a significantly decreased rate of death overtime. Age adjusted mortality rates decreased from $0.4 / 100$ personyears (CI: $0.24-0.64$ ) in $2001-2006$ period to $0.27 / 100$ personyears (CI: $0.13-0.52$ ) in $2007-2012$ and to $0.07 / 100$ personyears (CI: 0.036-3.5) in 2013-2018 (Table 2). Poisson regression model adjusted for sex, age at the first medical examination, place of birth, use of cART, viral load, and $\mathrm{CD} 4^{+} \mathrm{T}$-lymphocytes percentage was used to compare death rates among the study periods. Significantly reduced rates of death were observed in children with high $\mathrm{CD} 4^{+}$T-lymphocyte percentage $(>15 \%)$ (Table 2). Differences in mortality risk between patients born before and after 1996 (year of cART introduction) were analysed, however there was no significant decrease in incidence rate ratio between these two cohorts (Table 2). Mortality risk in children not in follow up from birth was higher, even if not significantly, than that in children followed up from birth (mortality IRR of children followed up after birth: 1.36; $P$ value 0.536 ) (Table 2). Reported causes of mortality were opportunistic infections ( $n$ $=8)$, specific or multi-organ failures $(n=5)$, cancer $(n=3)$, sepsis $(n=3)$, wasting syndrome $(n=2)$, cardiomyopathy and cardiac disease $(n=2)$, acute pulmonary oedema $(n=2)$, massive haemorrhages $(n=1)$, consequences of encephalopathy $(n=1)$, lactic acidosis $(n=1)$, lymphoid interstitial pneumonia $(n=$
$1)$, not known $(n=3)$. Fifteen out of 26 dead children (58\%) died when they were $>10$ years old while 6 out of $26(23 \%)$ died when they were $\leq 1$-year-old. Only eight (30.8\%) of the 26 dead children were followed up from birth. Nineteen $(73 \%)$ had initiated cART at age $\geq 6$ months. 6 children (23\%) were treated for $<30$ days before death, 12 (46\%) for $\geq 10$ years and $7(27 \%)$ for $>1$ year but $<10$ years. Almost all the children $(n=23 / 26 ; 88 \%)$ presented detectable $\mathrm{VL}$ at the last cheque before death and 15/26 children (58\%) had $\mathrm{CD} 4^{+} \mathrm{T}$-cell counts $<15 \%$ at last cheque. Only three children had undetectable VL at the last cheque before death. However, in these 3 patients, VL reported 12-18 months earlier were detectable (Table 3).

\section{Modifications of Clinical Event Rates}

Progressive significant reductions in CDC class B and C clinical event rates were observed during the study periods (Table 4). One hundred eighty class $B$ events occurred during the first period (4.31/100 person-years), while only 25 were observed in 2013-2018 (1.78/100 person-years), demonstrating a significant decrease over time $(P<0.0001)$. Class $C$ events were 229 in the first period (5.48/100 person-years) and considerably decreased $(P<0.0001)$ to 42 in the last one $(2.99 / 100$ person-years). Poisson regression model adjusted for timing of follow up and date of birth (before or after 1996) was used to compare class B and C event rates among the study periods. We noticed that the IRR for both $\mathrm{B}$ and $\mathrm{C}$ clinical events was significantly lower in children followed up from birth, as well as being progressively lower in 
TABLE 6 | Rates of the specific clinical events by calendar period and rate ratio (adjusted for age and repeated events in the same patient).

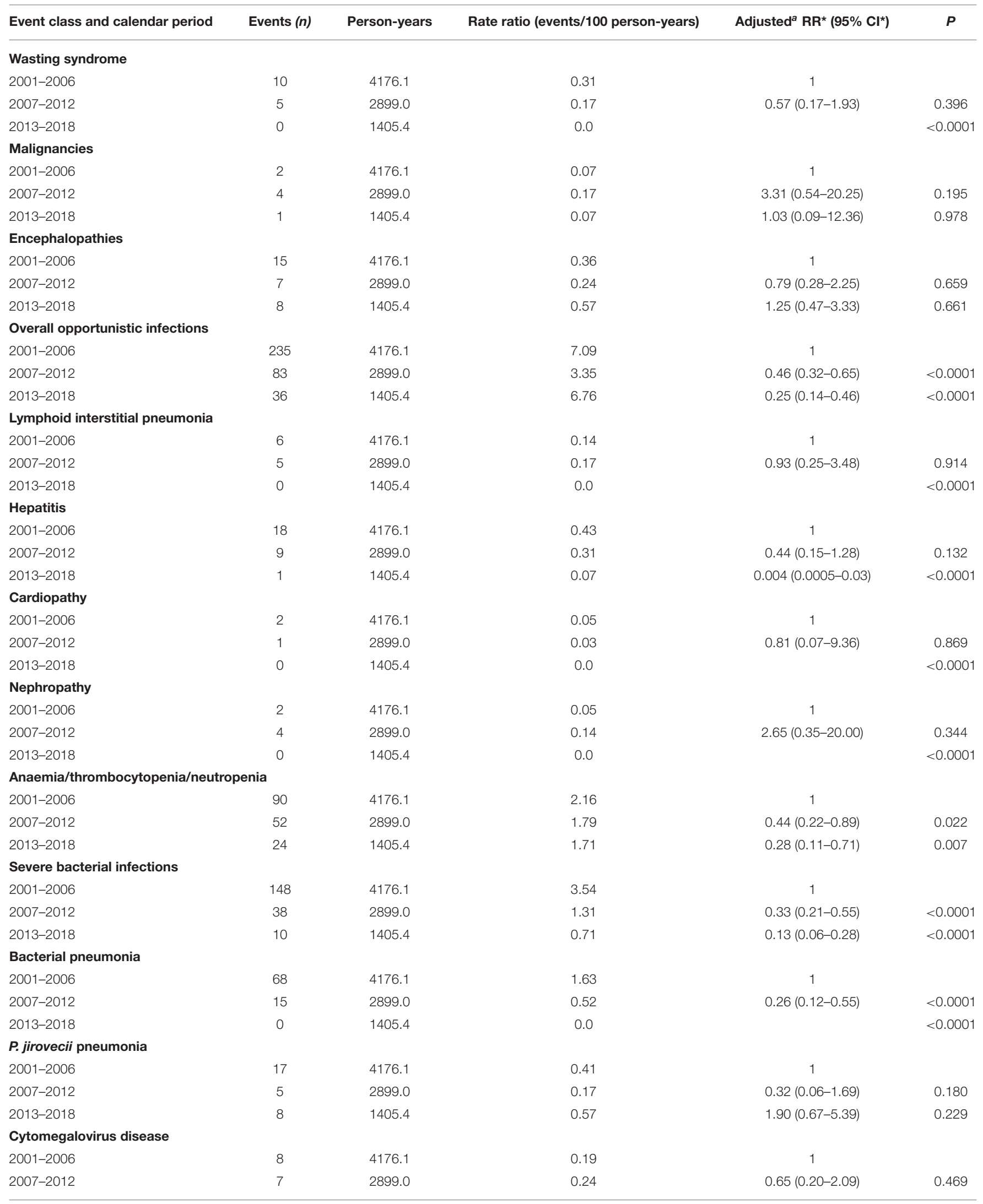


TABLE 6 | Continued

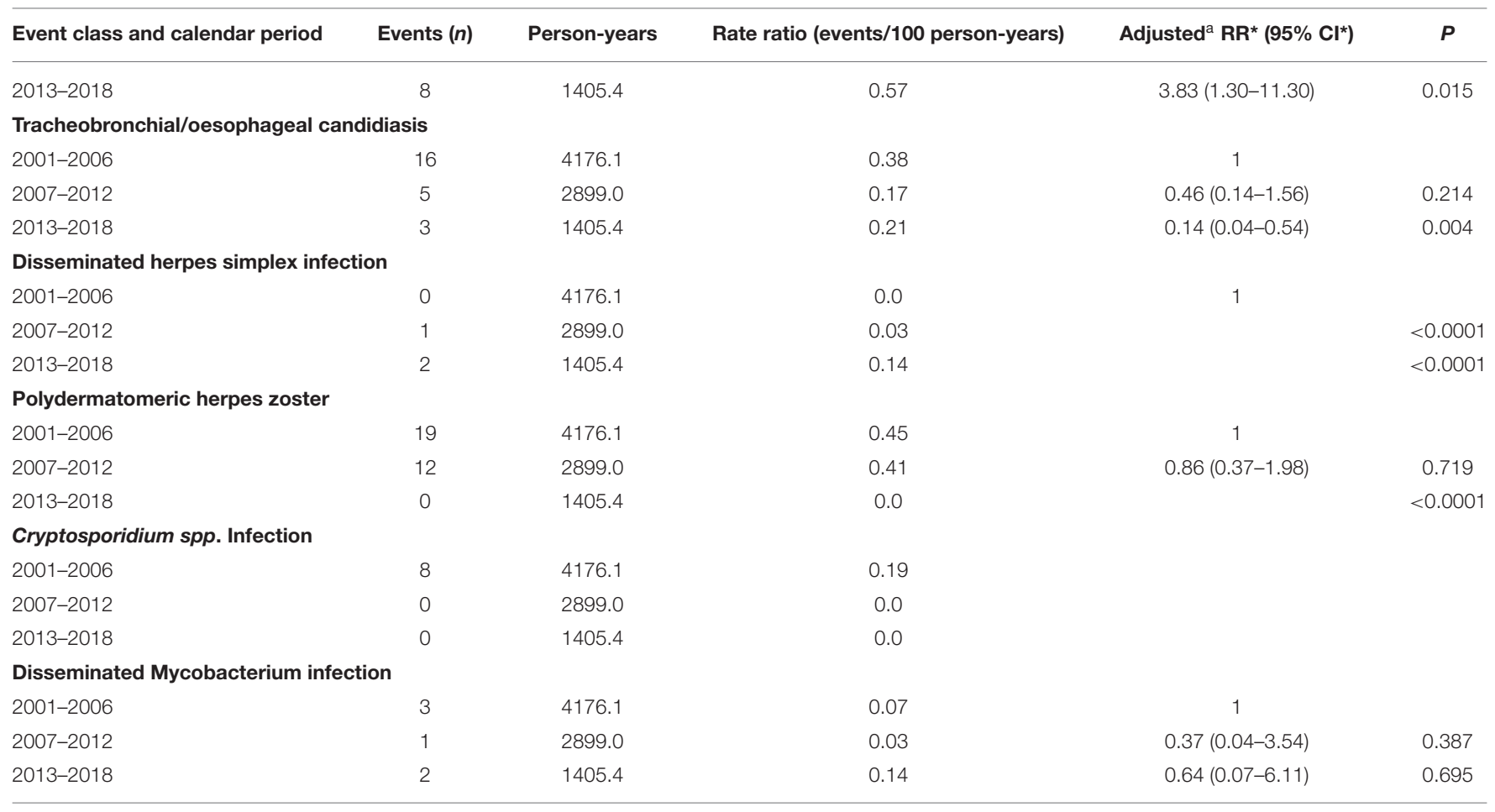

${ }^{\star} R R$, rate ratio; $\mathrm{Cl}$, confidence interval.

${ }^{a}$ Adjusted for age and repeated events in the same patients.

more recent calendar periods. On the other hand, children born after 1996 didn't have significantly decreased incidence rates of class B and C events (Table 5).

Rates for specific events by calendar period are reported in Table 6. During the first calendar period, OIs (7.09/100 person-years) were the most common events: among them, severe bacterial infections (3.54/100 person-years), bacterial pneumonia (1.63/100 person-years) and polydermatomeric herpes zoster $(0.45 / 100$ person-years) were the most frequent. Other commonly reported events were haematological abnormalities (2.16/100 person-years). During the intermediate (2007-2012) and the last (2013-2018) calendar periods, many clinical event rates decreased. However, OIs, even if significantly reduced over time, remained the most frequent events still in 2013-2018, occurring at the rate of 6.76/100 person-years. Among OIs, the most common ones during the last calendar period were severe bacterial infections $(0.71 / 100$ personyears), $P$. jirovecii pneumonia (0.57/100 person-years) and cytomegalovirus disease $(0.57 / 100$ person-years) (Table 6). The proportion of $P$. jirovecii pneumonia and CMV disease were not decreasing during the three study periods, while all the others OIs drastically decreased overtime. Analysing data about these two opportunistic infections, we found that in the $70 \%$ of children $P$. jirovecii pneumonia and HIV infections had the same date of diagnosis, as well as in $60 \%$ of children with cytomegalovirus disease. The majority of children presented detectable VL when OIs occurred: 210 children out of 296 (70.9\%) during the first calendar period, 52 children out of 97 (53.6\%) during the second calendar period and 62 children out of 95 (65.3\%) during the third calendar period. However, OIs occurred also in a minority of children with undetectable viremia [ 25 out of $296(8.4 \%)$ in the first calendar period, 19 out of $97(19.6 \%)$ in the second calendar period and 12 out of 95 (12.6\%) in the third calendar period].

Significantly reduced rates of OIs were observed in children belonging to the more recent calendar periods and with high CD $4^{+}$T-lymphocyte percentage $(>15 \%)$. At the same time, IRR was higher in children not followed up from birth, from abroad and with detectable viral loads (Table 7).

Seven cancers have been reported from 2001 to 2018: two in the first calendar period, four in the intermediate period and only one in the last calendar period. During the first calendar period cancers occurred at the rate of $0.07 / 100$ person-years, at the rate of $0.17 / 100$ person-years during the intermediate period (adjusted RR 3.31; CI: $0.54-20.25$ ) and at the rate of $0.07 / 100$ person-years during the last calendar period (adjusted RR 1.03; CI: 0.09-12.36) (Table 8). No significant reduction in the rates of cancers was observed in relation to sex, starting of follow up, child's origin, use of cART, VL, and $\mathrm{CD}^{+}{ }^{+}$T-lymphocyte percentage (Table 9).

Overall, non-Hodgkin B-cell lymphoma $(n=2)$, Burkitt lymphoma $(n=2)$, Kaposi sarcoma $(n=2)$, and Hodgkin lymphoma $(n=1)$ were observed. Five out of seven cancers (71.4\%) occurred in children who had detectable VL at the last cheque performed before cancer occurrence. At the same time, four children out of seven $(57.1 \%)$ presented high $\mathrm{CD}^{+} \mathrm{T}$ cell counts $(>25 \%)$ at the last cheque. Moreover, five children 
TABLE 7 | Opportunistic infections rates among the study periods, adjusted for sex, starting of follow up, child's origin, use of cART, viral load, and CD4+\%.

\begin{tabular}{|c|c|c|c|c|c|c|}
\hline Factors & Events $(n)$ & Person-years & Univariate IRR ${ }^{\star}\left(95 \% \mathrm{Cl}^{\star}\right)$ & $P$ & Multivariate IRR* $\left(95 \% \mathrm{Cl}^{\star}\right)$ & $\boldsymbol{P}$ \\
\hline \multicolumn{7}{|l|}{ Period } \\
\hline 2001-2006 & 235 & 4539.4 & 1 & & 1 & \\
\hline 2007-2012 & 83 & 2981.7 & $0.46(0.32-0.65)$ & $<0.0001$ & $0.42(0.29-0.63)$ & $<0.0001$ \\
\hline 2013-2018 & 36 & 1462.4 & $0.25(0.14-0.46)$ & $<0.0001$ & $0.21(0.11-0.39)$ & $<0.0001$ \\
\hline \multicolumn{7}{|l|}{ Sex } \\
\hline \multicolumn{7}{|l|}{ Follow-up } \\
\hline From & 79 & 3473.6 & 1 & & 1 & \\
\hline After birth & 275 & 5509.9 & $2.01(1.39-2.90)$ & $<0.0001$ & $1.79(1.25-2.56)$ & 0.002 \\
\hline \multicolumn{7}{|l|}{ Place of birth } \\
\hline Italy & 264 & 7397.9 & 1 & & 1 & \\
\hline Yes & 215 & 6097.7 & $1.09(0.82-1.46)$ & 0.540 & & \\
\hline \multicolumn{7}{|l|}{ Viral load } \\
\hline Undetectable & 35 & 2809.9 & 1 & & 1 & \\
\hline Detectable & 134 & 2164.3 & $4.30(2.91-6.36)$ & $<0.0001$ & $2.80(1.88-4.20)$ & $<0.0001$ \\
\hline Missing & 185 & 4009.4 & $2.62(1.81-3.81)$ & $<0.0001$ & $1.77(1.09-2.88)$ & 0.021 \\
\hline \multicolumn{7}{|c|}{$\mathrm{CD4}^{+}$T-lymphocyte percentage at the last cheque } \\
\hline$\leq 15 \%$ & 46 & 422.5 & 1 & & 1 & \\
\hline$>15 \%$ & 108 & 4324.6 & $0.24(0.16-0.35)$ & $<0.0001$ & $0.40(0.27-0.59)$ & $<0.0001$ \\
\hline Missing & 200 & 4236.4 & $0.37(0.26-0.54)$ & $<0.0001$ & $0.82(0.50-1.35)$ & 0.445 \\
\hline
\end{tabular}

(Poisson regression model adjusted for age and repeated events in the same subject).

*IRR, incidence rate ratio; $\mathrm{Cl}$, confidence interval.

with cancer out of seven (71.4\%) were on cART for more than 5 years before the occurrence of the tumour (Table 8). HIV1 encephalopathy was observed in 25 children: 15 in the first study period, 7 in the second one and 8 in the third one. Incidence rates of HIV-1 encephalopathy were: $0.36 / 100$ personyears during the first study period, $0.24 / 100$ person-years during the second one and $0.57 / 100$ person-years during the third one, with no significant reduction overtime (Table 6). All the cases were newly diagnosed in each period and never recorded previously. Most cases of encephalopathy (20 out of 25, i.e., $80 \%$ ) occurred in children who were not followed up from birth. Moreover, we observed that six children aged from 0 to 4 years old reported psychomotor delay (non-meeting CDC diagnostic criteria for HIV-1 encephalopathy): acquired motor deficits, failure to attain or loss of psychomotor developmental milestones, neurocognitive delay.

\section{DISCUSSION}

This study described changes in mortality rates, causes of death, and clinical events during the most recent years of the cART era (from 2001 to 2018). Mortality rates significantly decreased over time, not only during our study calendar periods but also in comparison to data reported in our previous study (19) (Figure 3).
Mortality risk in the cART era is far lower than in the pre-cART era, as previously reported (23-25). However, even though life expectation of perinatally HIV-1 infected children has lengthened and mortality rates in Western European countries such as Netherlands and Spain $(26,27)$ are decreasing $(0.3$ per 100 person-years from 1996 to 2012 and 0.0 in 2009, respectively), deaths have not yet disappeared.

It is already well-known that early diagnosis, strict follow up from birth, early, and effective therapy is fundamental to keep the disease under control and to prevent death and progression toward AIDS $(11,12)$. Indeed, significantly reduced rates of death were observed in children with high $\mathrm{CD} 4^{+}$T-lymphocyte percentage $(>15 \%)$. At the same time, almost all the dead children $(88.5 \%)$ presented detectable VL at the last cheque before death, and more than half had low $\mathrm{CD} 4^{+} \mathrm{T}$-cell counts $(<15 \%)$ at last cheque, confirming current data in literature (15, $16,28-30)$. Prior to the accessibility to cART in Europe, almost $20 \%$ of infants experienced early disease progression in the first year of life and $10 \%$ died $(45,46)$. The South African controlled randomised trial and the European collaborative cohort study demonstrated that early use of cART (before 5 or 3 months of life, respectively) slows the progression of the disease (12). Indeed, AIDS events precociously occurred (before the age of 2 years) in children treated after 3 months, while the rate of occurrence of AIDS or death of infants belatedly treated was similar to historical 
TABLE 8 | Characteristics of malignancies occurred in the study population from 2001 to 2018.

\begin{tabular}{|c|c|c|c|c|c|c|c|c|c|c|c|c|c|}
\hline Sex & $\begin{array}{l}\text { Child's } \\
\text { origin/Mother's } \\
\text { origin }\end{array}$ & $\begin{array}{l}\text { Age at first } \\
\text { observation }\end{array}$ & $\begin{array}{c}\text { First } \\
\text { observation }\end{array}$ & $\begin{array}{l}\text { Follow } \\
\text { up }\end{array}$ & $\begin{array}{l}\text { Clinical and } \\
\text { immunological } \\
\text { classes }\end{array}$ & $\begin{array}{l}\text { Status (year } \\
\text { of death) }\end{array}$ & $\begin{array}{l}\text { Type of } \\
\text { cancer }\end{array}$ & $\begin{array}{c}\text { Year of the } \\
\text { event }\end{array}$ & $\begin{array}{l}\text { Age at the } \\
\text { event } \\
\text { [years] }\end{array}$ & $\begin{array}{l}\text { Therapy at } \\
\text { the } \\
\text { occurrence } \\
\text { of cancer } \\
\text { (starting } \\
\text { date) }\end{array}$ & $\begin{array}{l}\text { Time on } \\
\text { treatment } \\
\text { before } \\
\text { cancer }\end{array}$ & $\begin{array}{l}\text { VL* at last cheque } \\
\text { [Detect./Undetect.] } \\
\text { (time between last } \\
\text { cheque and cancer) }\end{array}$ & $\begin{array}{l}\mathrm{CD}^{+} \text {T-cell } \\
\text { percentage at } \\
\text { last cheque } \\
\text { (time between } \\
\text { last cheque } \\
\text { and cancer) }\end{array}$ \\
\hline M & Italy/ Italy & $0 \mathrm{~m}$ & 1988 & $\begin{array}{l}\text { From } \\
\text { birth }\end{array}$ & C 2 & Adult care & $\begin{array}{l}\text { Non-Hodg. } \\
\text { B-cell lymph. }\end{array}$ & 2003 & 14 & $\begin{array}{l}\text { DDI+ } \\
3 T C+ \\
\text { LPV+ } \\
\text { RTV (2003) }\end{array}$ & $13 y$ & Detect., (0 m) & $31 \%(12 \mathrm{~m})$ \\
\hline M & Italy/ Italy & $6 m$ & 1994 & $\begin{array}{l}\text { After } \\
\text { birth }\end{array}$ & C 3 & Adult care & Burkitt lymph. & 2007 & 14 & $\begin{array}{l}\text { FTC+ } \\
\text { TDF+ } \\
\text { SQV+ } \\
\text { RTV+ } \\
\text { ATV+ } \\
\text { T20 (2007) }\end{array}$ & $13 y$ & Undet., (1 m) & $7 \%(13 m)$ \\
\hline M & Italy/taly & $0 \mathrm{~m}$ & 1994 & $\begin{array}{l}\text { From } \\
\text { birth }\end{array}$ & C 2 & Dead (2009) & Burkitt lymph. & 2009 & 15 & $\begin{array}{l}\text { FTC+ } \\
\text { TDF+ } \\
\text { LPV+ } \\
\text { RTV (2007) }\end{array}$ & $14 \mathrm{y}$ & Undet., (0 m) & $35 \%$ (1 m) \\
\hline $\mathrm{F}$ & Italy/ Italy & $0 m$ & 2000 & $\begin{array}{l}\text { From } \\
\text { birth }\end{array}$ & C 3 & Adult care & Kaposi sarc. & 2001 & 1 & $\begin{array}{l}\mathrm{DDI}+ \\
\mathrm{D} 4 \mathrm{~T}(2000)\end{array}$ & $11 \mathrm{~m}$ & Detect., (2 m) & $2 \%(1 \mathrm{~m})$ \\
\hline $\mathrm{F}$ & Italy/ Italy & $6 y$ & 2002 & $\begin{array}{l}\text { After } \\
\text { birth }\end{array}$ & A 2 & Dead (2012) & $\begin{array}{l}\text { Non-Hodg. } \\
\text { B-cell lymph. }\end{array}$ & 2012 & 15 & $\begin{array}{l}\text { DDI+ } \\
\text { D4T+ } \\
\text { LPV+ } \\
\text { RTV (2007) }\end{array}$ & $9 y$ & Detect., (2 y) & $31 \%(2$ y $1 \mathrm{~m})$ \\
\hline $\mathrm{F}$ & Italy/ Italy & 13 y $5 \mathrm{~m}$ & 2010 & $\begin{array}{l}\text { After } \\
\text { birth }\end{array}$ & C 3 & Dead (2012) & Kaposi sarc. & 2010 & 13 & $\begin{array}{l}\text { DDI+ } \\
\text { 3TC+ } \\
\text { ATV (2010) }\end{array}$ & $<1 \mathrm{~m}$ & Detect., $(0 \mathrm{~m})$ & $5.6 \%(0 \mathrm{~m})$ \\
\hline F & Italy/ Italy & $15 \mathrm{~m}$ & 2010 & $\begin{array}{l}\text { After } \\
\text { birth }\end{array}$ & A 1 & On follow up & Hodg. lymph. & 2015 & 6 & $\begin{array}{l}\text { ABC+ } \\
\text { 3TC+ } \\
\text { ATV (2014) }\end{array}$ & 3 y $8 m$ & Detect., (3 y) & $27 \%$ (3 y) \\
\hline
\end{tabular}

*Hodg, Hodgkin; Iymph, Iymphoma; sarc, sarcoma; VL, viral load; detect., detectable; undet., undetectable; y, years; m, months; DDI, didanosine; 3TC, lamivudine; LPV, lopinavir; RTV, ritonavir; FTC, emtricitabine; TDF, tenofovir disoproxil, SQV, saquinavir; ATV, atazanavir; T20, enfuvirtide; D4T stavudine; ABC, abacavir. 
TABLE 9 | Malignancies rates among the study periods, adjusted for sex, starting of follow up, child's origin, use of HAART, viral load and CD4+ T-lymphocyte percentage (Poisson regression model).

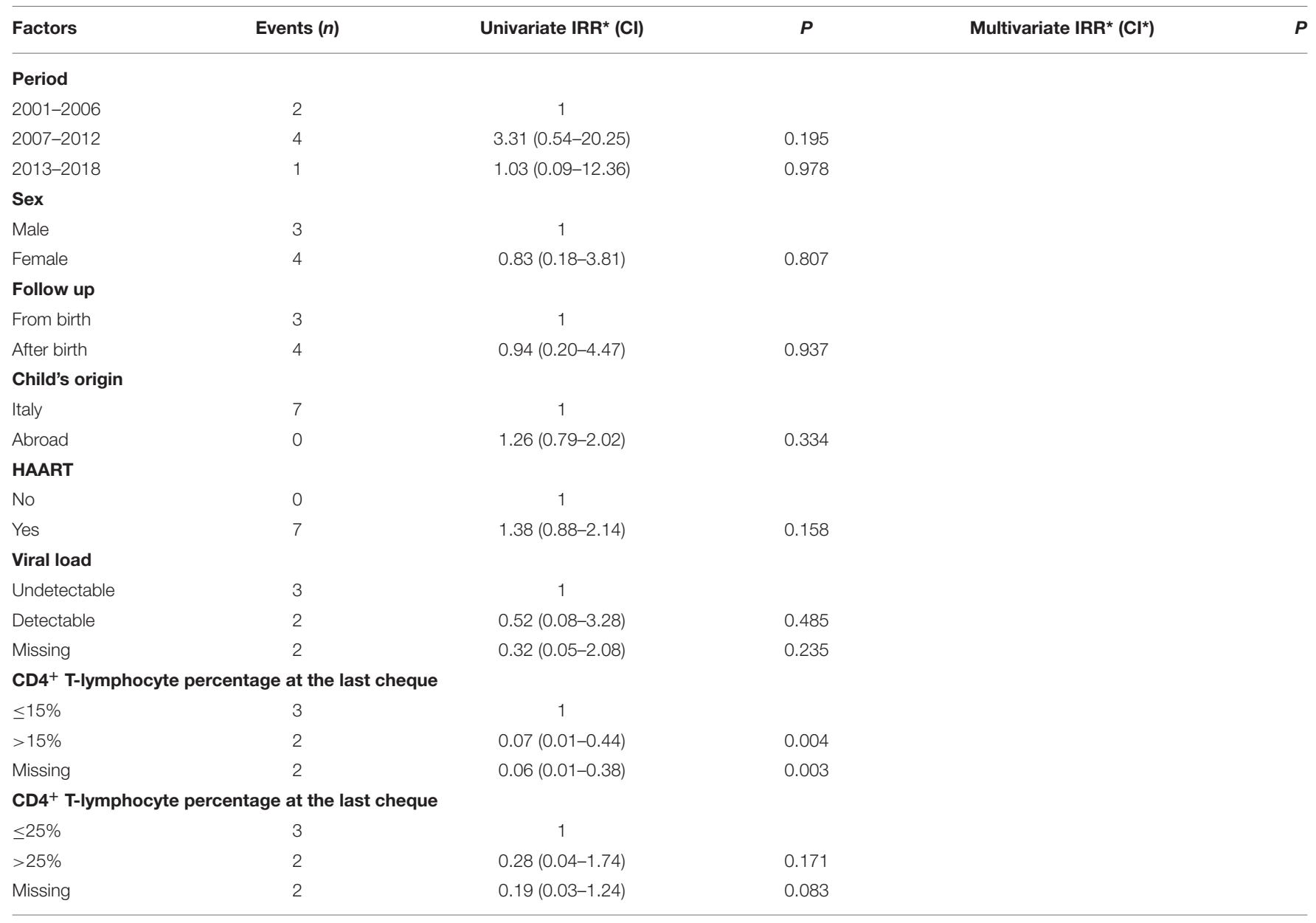

*IRR, incidence rate ratio; $\mathrm{Cl}$, confidence interval.

reports of HIV infected infants not treated with cART $(47,48)$. Early initiation of cART was also associated with a significantly reduced risk of HIV encephalopathy (49) as well as with limited immunological progression (14). In line with these results, we noticed that mortality risk in children not in follow up from birth was higher (even if not significantly) than in children followed up from birth and, therefore, early treated with cART. However, no difference in mortality risk was found between patients born before and after 1996 (year of cART introduction). Analysing more in detail the characteristics of dead children, the mortality data are not very reassuring if considering that more than $70 \%$ of dead children had initiated treatment when they were $\geq 6$ months old, even if 24 out of the 26 dead children (92.3\%) were born in Italy. On the one hand, this result confirms that children who are belatedly diagnosed and treated are at greater risk of death in percentage terms, on the other hand it highlights how even in a Western country like Italy many children still escape an early diagnosis and treatment from birth.

It must also be highlighted that more than one-fifth of the dead children had received cART for less than a month and almost the same amount for $<10$ years in any case.
Unfortunately, we do not have enough information to recognise the causes of these failures (i.e., poor adherence, viral resistance).

A deep decrease in class $\mathrm{B}$ and $\mathrm{C}$ clinical events occurred during the three study periods (from 2001 to 2018). Moreover, comparing clinical events occurred from 2001 to 2018 to the events occurred from 1985 to 2005 (19), a significant reduction in both class $\mathrm{B}$ and $\mathrm{C}$ events can be noticed (Figure 4). As already reported in literature $(11,12)$, class $\mathrm{B}$ and $\mathrm{C}$ event rates were significantly reduced in children followed up from birth, confirming the importance of early diagnosis and treatment to slow disease progression.

Cancer rates significantly decreased compared to those of the first two periods of the previous study (19), but remained almost stable if compared to the third calendar period of the same study (19) and during our three study periods. As reported in a recent case-control study of 1,307 perinatally HIV1 infected Spanish children (31), and in the US HIV/AIDS Cancer Match Study (32), the overall rate of cancers did not significantly change in the last years, remaining high even in the cART era. However, in contrast with literature, which 


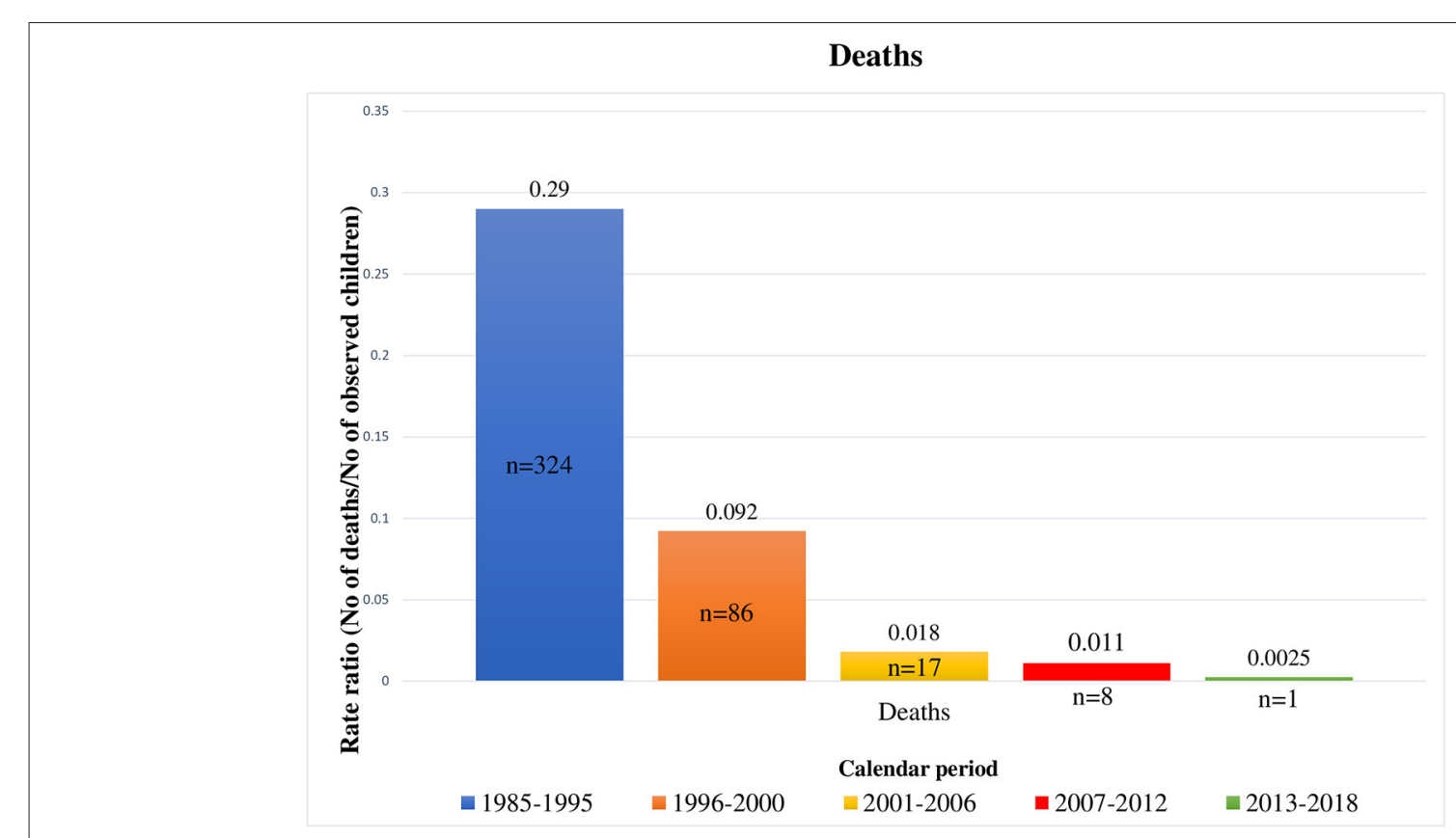

FIGURE 3 | Deaths occurred in HIV-1 infected children by calendar period, from 1985 to 2018 [1985-1995 and 1996-2000 periods refer to our previous results (18)].

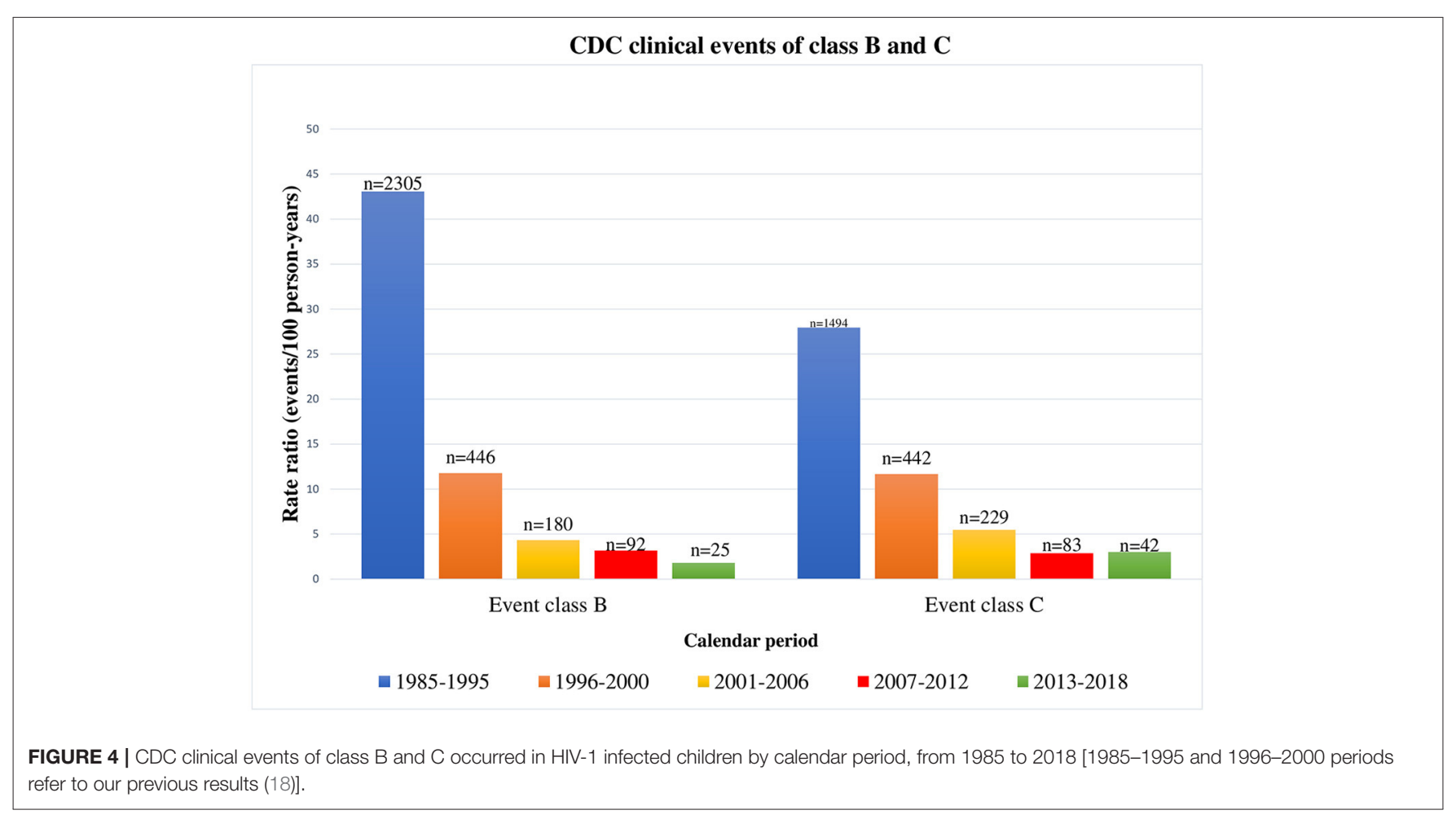

reported that AIDS related malignancies declined during the cART era while the incidence of non-AIDS related cancers increased over time $(31,33)$, in our study, the most common cancers remained Burkitt lymphoma, Kaposi sarcoma and nonHodgkin B-cell lymphoma, as observed in low-income-resource countries $(34,35)$. No case of leiomyosarcoma was found, even if it is now the second most frequent malignancy in HIV-infected children in the USA (36). Any significant relation between the immunovirological status (expressed by $\mathrm{CD} 4^{+} \mathrm{T}$-cell count and viral load) and cancer risk was found. Even if $71.4 \%$ of the 


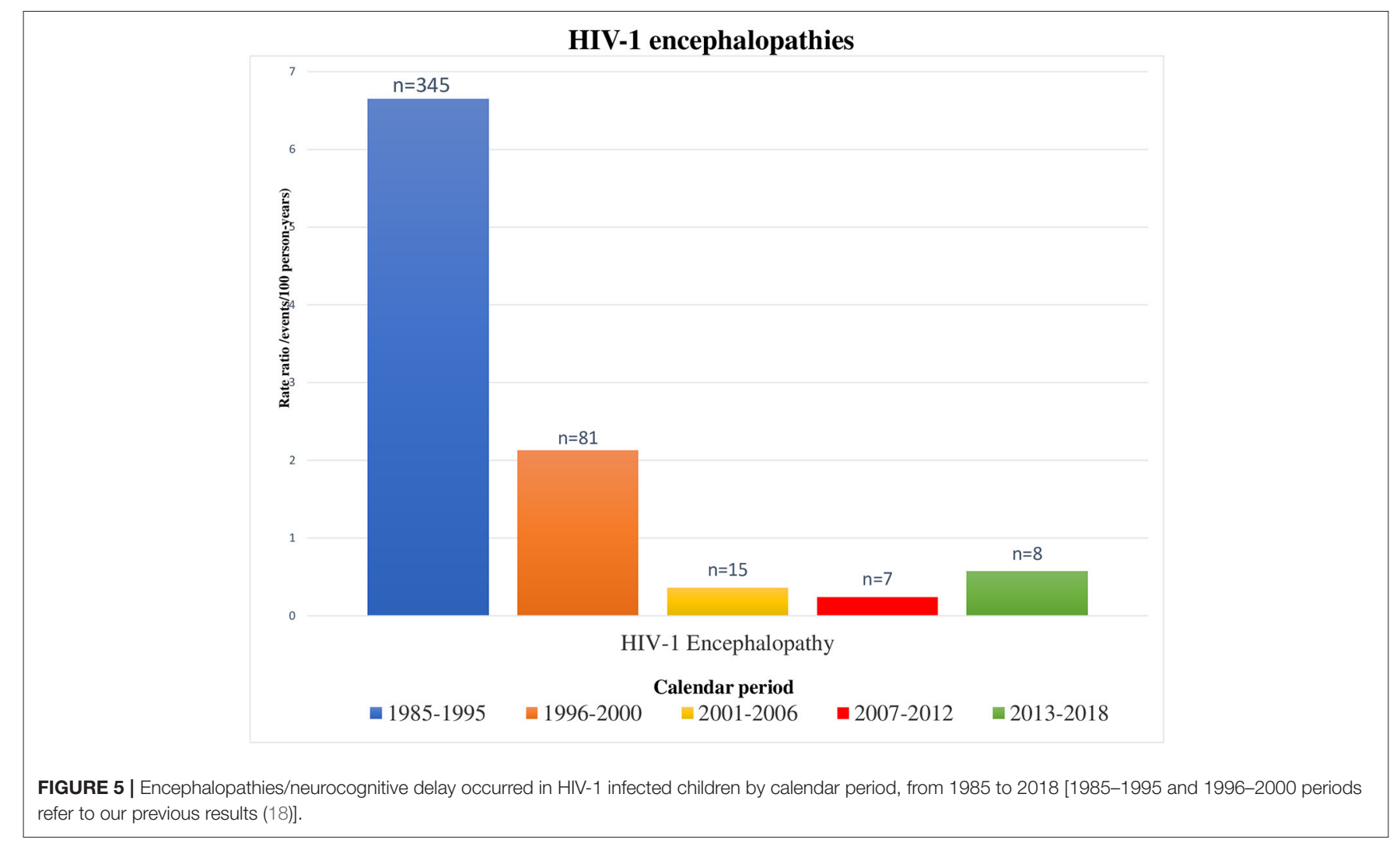

children were on treatment for more than 5 years before cancer occurrence, almost three-quarters of the cancers occurred in children with detectable viral loads at the last cheque, suggesting, despite the long time spent in treatment, poor adherence to the therapy itself.

OIs rates significantly reduced during the cART era, in parallel to the restoration of the immune system activity $(15,17,37$, 38). Indeed, OIs more frequently occurred in children with detectable viral loads and low $\mathrm{CD} 4^{\wedge}+$ T-lymphocyte counts $(<25 \%)$. Overall OIs, HIV-1 hepatitis, lymphoid interstitial pneumonia, severe bacterial infections, bacterial pneumonia, disseminated herpes simplex infection, and polydermatomeric herpes zoster rates have been significantly reduced from 1985 to 2018 ( $P<0.0001)$. On the other hand, Pneumocystis jirovecii pneumonia and CMV infection rates have not been significantly reduced over time. They are probably not decreasing (differently from other OIs) in relation to two factors: certainly, diagnostic techniques have improved thanks to implementation of PCR tests; moreover, these types of infection are often onset diagnosis of HIV infection, when viral loads are obviously still detectable. OIs also occurred in children with undetectable viremia. Therefore, it should be crucial to investigate the functional immunologic aspects, too. As already reported in the literature, B-cell and T-cell profiles alterations could correlate with the worse immune response to pathogens (39-42). In our study, HIV-1 encephalopathy was observed in 25 children. Despite a significant reduction $(P<0.0001)$ observed in our previous study (19) from 1985 to 2005 (probably related to the largescale introduction of cART), there were no statistically significant reductions in HIV-1 encephalopathy incidence from 2001 to 2018 (Figure 5).

Eighty percent of encephalopathies occurred in children who were not followed up from birth. We also observed children who developed acquired motor deficits, failure to attain or loss of psychomotor developmental milestones, neurocognitive delay (non-meeting CDC diagnostic criteria for HIV-1 encephalopathy). This finding reflects what observed in other recent studies: even if the introduction of cART reduced the rates of HIV-1-related encephalopathy $(43,44,50)$, milder neurocognitive deficits (lower total intelligence quotient, language impairment, poorer working memory, gross and fine motor functioning, visual-motor impairment) are diagnosed more and more frequently (51-56).

Our population study was conducted on a representative cohort of not-selected children, prospectively followed up. Therefore, this assessment reflects what is actually occurring in the paediatric population and could be helpful for experts who are taking care of perinatally HIV-1 infected children in Western countries. The study can be biassed in various ways: underreporting is possible, only basic data can be collected; children lost to follow-up were excluded from the study, therefore if they experienced clinical events during the study period, these data haven't been reported; data about HIV-infected people aged $>18$ years old are missing; diagnoses of clinical events have been collected in numerous different hospital centres implying a certain heterogeneity in the diagnostic criteria (in particular for clinical events as HIV-1 encephalopathies, whose diagnosis is purely clinical.) However, we believe that none of these potential 
biases significantly affected our results. The Italian Register for HIV Infection in Children is one of the largest cohorts of children perinatally infected with HIV-1 and highly representative of the entire population of Italian HIV-1-infected children (9). In conclusion, we provide evidence for a progressive reduction in mortality and morbidity in perinatally HIV-1 infected children during the cART era in a Western country. At the same time, we underline that the number of deaths has not completely reset, although the extensive use of cART and, despite the longer life expectancy for HIV-1 infected children during the cART era, severe bacterial infections and cancers continue to occur at higher rates than in general paediatric population. The majority of children who died or developed HIV-related clinical events presented detectable viral loads. This finding suggests that there is probably a serious problem with adherence to therapy and considerable efforts still need to be made in order to implement strategies to improve the adherence itself (57). Our data shows that we cannot yet consider HIV infection completely harmless. It must be underlined that only almost $30 \%$ of the dead children were followed from birth and that the majority of them had belatedly initiated cART (at age $\geq 6$ months), confirming that late diagnosis and treatment correlates with higher mortality. Mortality risk and class B and C clinical events incidence were higher in children not followed up from birth. Therefore, it seems to be clear that many HIV related events probably wouldn't have occurred if diagnosis and therapy were more precocious and if adherence to the treatment was greater. As exposed in a recent study by Di Biagio et al. (58), numerous efforts, both medical and organisational, are still needed to improve the survival and quality of life of children with perinatal HIV-1 infection. For this purpose, it is essential to ensure early diagnoses, to start treatment early and to improve adherence to therapy in the paediatric population.

\section{DATA AVAILABILITY STATEMENT}

Publicly available datasets were analysed in this study. This data can be found here: Italian Register for HIV Infection in Children.

\section{REFERENCES}

1. Engelman A, Cherepanov P. The structural biology of HIV-1: mechanistic and therapeutic insights. Nat Rev Microbiol. (2012) 10:279-90. doi: $10.1038 /$ nrmicro2747

2. Emedicine. Antiretroviral Therapy for HIV Infection: Overview, FDAApproved Antivirals and Regimens, Complete Regimen Combination ARTs. Available online at: https://emedicine.medscape.com/article/1533218overview (accessed October 30, 2019).

3. World Health Organization, WHO. Transition To New Antiretroviral Drugs in Hiv Programmes: Clinical and Programmatic Considerations. (2015). Available online at: https://www.who.int/hiv/pub/toolkits/transition-to-newarv-technical-update/en/ (accessed October 30, 2019).

4. Paediatric care and treatment. UNICEF Data. Available online at: https://data. unicef.org/topic/hivaids/paediatric-treatment-and-care/ (accessed October 30, 2019).

5. World Health Organization. WHO. Data and Statistics WHO. (2019). Available online at: https://www.who.int/hiv/data/en/ (accessed September 23, 2019).

\section{ETHICS STATEMENT}

The studies involving human participants were reviewed and approved by Ethics Committee University of Florence. Written informed consent to participate in this study was provided by the participants' legal guardian/next of kin.

\section{AUTHOR CONTRIBUTIONS}

EC and FL contributed to conception, design of the study, and wrote the first draught of the manuscript. CL performed the statistical analysis. All authors contributed to manuscript revision, read, and approved the submitted version.

\section{FUNDING}

This study was funded by the University of Florence.

\section{ITALIAN REGISTER FOR HIV INFECTION IN CHILDREN}

Elena Chiappini, Luisa Galli, Pier Angelo Tovo, Carlo Giaquinto, Catiuscia Lisi. Other collaborators who refer to the Italian Register for HIV Infection in Children and aided the efforts of the authors: Maurizio Ruggeri (Bergamo), Francesco Baldi, Giacomo Faldella (Bologna), Piergiorgio Chiriacò (Brindisi), Carlo Dessì (Cagliari), Maria Grazia Pantò (Catania), Elisa Anastasio (Catanzaro), Luisa Abbagnato (Como), Maria Rita Govoni (Ferrara), Maurizio Bigi (Forlì), Elisabetta Bondi (Genova), Riccardo Borea, Giovanni Cenderello (Imperia), Donato Tommasi (Lecce), Raffaella Pinzani (Milano) Ernesto Renato Dalle Nogare, Marcello Saitta (Palermo), Leonardo Felici (Pesaro), Rita Consolini (Pisa), Angelo Antonellini (Ravenna), Gianfranco Anzidei, Orazio Genovese, Salvatore Catania, Anna Maria Casadei (Roma), Paolina Olmeo (Sassari) Letizia Cristiano (Taranto), Vincenzo Portelli (Trapani), Marco Rabusin (Trieste), Annamaria Plebani (Varese).
6. Dirajlal-Fargo S, Koay WLA, Rakhmanina N. Pediatric antiretroviral therapy. Handb Exp Pharmacol. (2020) 261:285-323. doi: 10.1007/164_2019_246

7. Penazzato M, Prendergast AJ, Muhe LM, Tindyebwa D, Abrams E. Optimisation of antiretroviral therapy in HIV-infected children under 3 years of age. Cochrane Database Syst Rev. (2014) 2014:CD004772. doi: 10.1002/14651858.CD004772.pub4

8. Gortmaker SL, Hughes M, Cervia J, Brady M, Johnson GM, Seage GR, et al. Effect of combination therapy including protease inhibitors on mortality among children and adolescents infected with HIV-1. N Engl J Med. (2002) 345:1522-8. doi: 10.1056/NEJMoa0 11157

9. de Martino M, Tovo PA, Balducci M, Galli L, Gabiano C, Rezza G, et al. Reduction in mortality with availability of antiretroviral therapy for children with perinatal HIV-1 infection. Italian Register for HIV Infection in Children and the Italian National AIDS Registry. JAMA. (2000) 284:190-7. doi: 10.1001/jama.284.2.190

10. Gibb DM. Decline in mortality, AIDS, and hospital admissions in perinatally HIV-1 infected children in the United Kingdom and Ireland. BMJ. (2003) 327:1019. doi: 10.1136/bmj.327.7422.1019 
11. Goetghebuer T, Haelterman E, Le Chenadec J, Dollfus C, Gibb D, Judd A, et al. Effect of early antiretroviral therapy on the risk of AIDS/death in HIV-infected infants. AIDS. (2009) 23:597-604. doi: 10.1097/QAD.0b013e328326ca37

12. Violari A, Cotton MF, Gibb DM, Babiker AG, Steyn J, Madhi SA, et al. CHER Study Team. Early antiretroviral therapy and mortality among HIV-infected infants. N Engl J Med. (2008) 359:2233-44. doi: 10.1056/NEJMoa0800971

13. Mahdavi S, Malyuta R, Semenenko I, Pilipenko T, Thorne C, Ukraine European Collaborative Study Group. Treatment and disease progression in a birth cohort of vertically HIV-1 infected children in Ukraine. BMC Pediatr. (2010) 10:85. doi: 10.1186/1471-2431-10-85

14. Newell ML, Patel D, Goetghebuer T, Thorne C, European Collaborative Study. $\mathrm{CD} 4$ cell response to antiretroviral therapy in children with vertically acquired HIV infection: is it associated with age at initiation? J Infect Dis. (2006) 193:954-62. doi: 10.1086/500842

15. Kapogiannis BG, Soe MM, Nesheim SR, Abrams EJ, Carter RJ, Farley J, et al. Mortality trends in the US perinatal AIDS collaborative transmission study (1986-2004). Clin Infect Dis. (2011) 53:1024-34. doi: 10.1093/cid/cir641

16. Viani RM, Araneta MRG, Deville JG, Spector SA. Decrease in hospitalization and mortality rates among children with perinatally acquired HIV type 1 infection receiving highly active antiretroviral therapy. Clin Infect Dis. (2004) 39:725-31. doi: $10.1086 / 423178$

17. Brady MT, Oleske JM, Williams PL, Elgie C, Mofenson LM, Dankner WM, et al. Declines in mortality rates and changes in causes of death in HIV-1infected children during the HAART era. J Acquir Immune Defic Syndr. (2010) 53:86-94. doi: 10.1097/QAI.0b013e3181b9869f

18. B-Lajoie M-R, Drouin O, Bartlett G, Nguyen Q, Low A, Gavriilidis G, et al. Incidence and prevalence of opportunistic and other infections and the Impact of Antiretroviral Therapy among HIV-infected children in low- and middle-income countries: a systematic review and meta-analysis. Clin Infect Dis. (2016) 62:1586-94. doi: 10.1093/cid/ciw139

19. Chiappini E, Galli L, Tovo PA, Gabiano C, Lisi C, Gattinara GC, et al. Changing patterns of clinical events in perinatally HIV-1infected children during the era of HAART. AIDS. (2007) 21:1607-15. doi: 10.1097/QAD.0b013e32823ecf5b

20. Italian guidelines for antiretroviral therapy in children with human immunodeficiency virus-type 1 infection. Acta Paediatr. (2007).

21. Aidsinfo. Brief|What's New in the Guidelines | Pediatric ARV. Available online at: https://aidsinfo.nih.gov/guidelines/brief-html/2/pediatric-arv/0 (accessed September 13, 2019).

22. Centers for Disease Control and Prevention. Guidelines for the use of antiretroviral agents in pediatric HIV infection. MMWR Morb Mortal Wkly Rep. (1998) 47:1-43.

23. Resino S, Resino R, Bellon JM, Micheloud D, Gutierrez MDG, Jose MI de, et al. Clinical outcomes improve with highly active antiretroviral therapy in vertically HIV type-1-infected children. Clin Infect Dis. (2006) 43:243-52. doi: $10.1086 / 505213$

24. Ramos AN, Matida LH, Hearst N, Heukelbach J. AIDS morbidity and mortality in brazilian children before and after highly active antiretroviral treatment implementation: an assessment of regional trends. Pediatr Infect Dis J. (2011) 30:773-7. doi: 10.1097/INF.0b013e31821b11ab

25. Judd A, Chappell E, Turkova A, Le Coeur S, Noguera-Julian A, Goetghebuer $\mathrm{T}$, et al. Long-term trends in mortality and AIDS-defining events after combination ART initiation among children and adolescents with perinatal HIV infection in 17 middle- and high-income countries in Europe and Thailand: a cohort study. PLoS Med. (2018) 15:1002491. doi: 10.1371/journal.pmed.1002491

26. Cohen S, Smit C, Van Rossum AMC, Fraaij PLA, Wolfs TFW, Geelen SPM, et al. Long-term response to combination antiretroviral therapy in HIVinfected children in the Netherlands registered from 1996 to 2012. AIDS. (2013) 27:2567-75. doi: 10.1097/01.aids.0000432451.75980.1b

27. Palladino C, Climent FJ, José MI De, Jimenez De Ory S, Bellón JM, Guillén S, et al. Causes of death in pediatric patients vertically infected by the human immunodeficiency virus type 1 in Madrid, Spain, from 1982 to mid-2009. Pediatr Infect Dis J. (2011) 30:495-500. doi: 10.1097/INF.0b013e318211399f

28. Lavreys L, Baeten JM, Chohan V, McClelland RS, Hassan WM, Richardson BA, et al. Higher set point plasma viral load and more-severe acute HIV Type 1 (HIV-1) Illness predict mortality among High-Risk HIV-1-infected African women. Clin Infect Dis. (2006) 42:1333-9. doi: 10.1086/503258
29. Palella FJ, Baker RK, Moorman AC, Chmiel JS, Wood KC, Brooks JT, et al. Mortality in the highly active antiretroviral therapy era: changing causes of death and disease in the HIV outpatient study. J Acquir Immune Defic Syndr. (2006) 43:27-34. doi: 10.1097/01.qai.0000233310.90484.16

30. Palumbo PE, Raskino C, Fiscus S, Pahwa S, Fowler MG, Spector SA, et al. Predictive value of quantitative plasma HIV RNA and CD4+ lymphocyte count in HIV-infected infants and children. JAMA. (1998) 279:756. doi: 10.1001/jama.279.10.756

31. Álvaro-Meca A, Micheloud D, Jensen J, Díaz A, García-Alvarez M, Resino S. Epidemiologic trends of cancer diagnoses among HIV-infected children in Spain from 1997 to 2008. Pediatr Infect Dis J. (2011) 30:764-8. doi: 10.1097/INF.0b013e31821ba148

32. Simard EP, Shiels MS, Bhatia K, Engels EA. Long-term cancer risk among people diagnosed with AIDS during childhood. Cancer Epidemiol Biomarkers Prev. (2012) 21:148-54 doi: 10.1158/1055-9965.EPI-11-0823

33. Chiappini E, Galli L, Tovo PA, Gabiano C, Lisi C, Giaquinto C, et al. Cancer rates after year 2000 significantly decrease in children with perinatal HIV infection: a study by the Italian Register for HIV infection in children. J Clin Oncol. (2007) 25:97-101. doi: 10.1200/JCO.2006.06.6506

34. Bohlius J, Maxwell N, Spoerri A, Wainwright R, Sawry S, Poole J, et al. Incidence of AIDS-defining and other cancers in HIV-positive children in South Africa record linkage study. Pediatr Infect Dis. (2016) 35:e164-70. doi: $10.1097 /$ INF.0000000000001117

35. Stefan DC, Stones DK. Children with cancer and HIV infection: what is different about them? J Pediatr Hematol Oncol. (2013) 35:590-6. doi: 10.1097/MPH.0b013e3182913e6a

36. Yin X, Wu T, Yan Y, Zhang H, Bu H. Treatment for leiomyosarcoma and leiomyoma in children with HIV infection. Cochrane Database Syst Rev. (2010) 5:7665. doi: 10.1002/14651858.CD007665.pub2

37. Nesheim SR, Kapogiannis BG, Soe MM, Sullivan KM, Abrams E, Farley J, et al. Trends in opportunistic infections in the pre and post highly active antiretroviral therapy Eras among HIV-infected children in the perinatal AIDS collaborative transmission study, 1986 2004. Pediatrics. (2007) 120:1009. doi: 10.1542/peds.2006-2052

38. Gona P, Van Dyke RB, Williams PL, Dankner WM, Chernoff MC, Nachman SA, et al. Incidence of opportunistic and other infections in HIV-infected children in the HAART Era. JAMA. (2006) 296:292-4. doi: 10.1001/jama.296.3.292

39. Mansoor N, Abel B, Scriba TJ, Hughes J, de Kock M, Tameris M, et al. Significantly skewed memory CD8+ T cell subsets in HIV-1 infected infants during the first year of life. Clin Immunol. (2009) 130:280-9. doi: 10.1016/j.clim.2008.09.006

40. Díaz L, Méndez-Lagares G, Correa-Rocha R, Pacheco YM, Ferrando-Martínez S, Ruiz-Mateos E, et al. Detectable viral load aggravates immunosenescence features of CD8 T-cell subsets in vertically HIV-infected children. J Acquir Immune Defic Syndr. (2012) 60:447-54. doi: 10.1097/QAI.0b013e31825 $9254 \mathrm{f}$

41. Moir S, Fauci AS. B cells in HIV infection and disease. Nat Rev Immunol. (2009) 9:235-45. doi: 10.1038/nri2524

42. Cagigi A, Rinaldi S, Di Martino A, Manno EC, Zangari P, Aquilani A, et al. Premature immune senescence during HIV-1 vertical infection relates with response to influenza vaccination. J Allergy Clin Immunol. (2014) 133:592-4. doi: 10.1016/j.jaci.2013.10.003

43. Patel K, Ming X, Williams PL, Robertson KR, Oleske JM, Seage GR, et al. Impact of HAART and CNSpenetrating antiretroviral regimens on HIV encephalopathy among perinatally infected children and adolescents. AIDS. (2009) 23:1893-901. doi: 10.1097/QAD.0b013e32832dc041

44. Wilmshurst JM, Hammond CK, Donald K, Hoare J, Cohen K, Eley B. NeuroAIDS in children. Handb Clin Neurol. (2018) 152:99-116. doi: 10.1016/B978-0-444-63849-6.00008-6

45. Saylor D, Dickens AM, Sacktor N, Haughey N, Slusher B, Pletnikov M, et al. HIV-associated neurocognitive disorder - Pathogenesis and prospects for treatment. Nat Rev Neurol. (2016) 12:234-48. doi: 10.1038/nrneurol.2016.27

46. The European Collaborative Study. Natural history of vertically acquired human immunodeficiency virus-1 infection. Pediatrics. (1994) 94:815-9.

47. European Collaborative Study. Children born to women with HIV-1 infection: natural history and risk of transmission. Lancet. (1991) 337:253-60. doi: 10.1016/0140-6736(91)90866-N 
48. Blanche S, Newell ML, Mayaux MJ, Dunn DT, Teglas JP, Rouzioux C, et al. Morbidity and mortality in European children vertically infected by HIV-1. The French Pediatric HIV Infection Study Group and European Collaborative Study. J Acquir Immune Defic Syndr Hum Retrovirol. (1997) 14:442-50. doi: 10.1097/00042560-199704150-00008

49. Faye A, Le Chenadec J, Dollfus C, Thuret I, Douard D, Firtion G, et al. Early versus deferred antiretroviral multidrug therapy in infants infected with HIV type 1. Clin Infect Dis. (2004) 39:1692-8 doi: 10.1086/425739

50. Malee KM, Chernoff MC, Sirois PA, Paige L, Garvie PA, Kammerer BL, et al. Impact of perinatally acquired HIV Disease upon longitudinal changes in memory and executive functioning. J Acquir Immune Defic Syndr. (2017) 75:455-64. doi: 10.1097/QAI.0000000000001441

51. Crowell CS, Huo Y, Tassiopoulos K, Malee KM, Yogev R, Hazra R, et al. Early viral suppression improves neurocognitive outcomes in HIVinfected children. AIDS. (2015) 29:295-304. doi: 10.1097/QAD.00000000000 00528

52. Lowick S, Sawry S, Meyers T. Neurodevelopmental delay among HIV-infected preschool children receiving antiretroviral therapy and healthy preschool children in Soweto, South Africa. Psychol Health Med. (2012) 17:599-610. doi: 10.1080/13548506.2011.648201

53. Smith R, Wilkins M. Perinatally acquired HIV infection: long-term neuropsychological consequences and challenges ahead. Child Neuropsychol. (2015) 21:234-68. doi: 10.1080/09297049.2014.898744

54. Cohen S, ter Stege JA, Geurtsen GJ, Scherpbier HJ, Kuijpers TW, Reiss P, et al. Poorer cognitive performance in perinatally HIV-Infected Children versus healthy socioeconomically matched controls. Clin Infect Dis. (2015) 60:1111-9. doi: 10.1093/cid/ciul144

55. Puthanakit $\mathrm{T}$, Ananworanich J, Vonthanak S, Kosalaraksa P, Hansudewechakul R, van der Lugt J, et al. Cognitive function and neurodevelopmental outcomes in HIV-infected children older than 1 year of age randomised to early versus deferred antiretroviral therapy. Pediatr Infect Dis J. (2013) 32:501-8. doi: 10.1097/INF.0b013e31827fb19d

56. Vreeman RC, Scanlon ML, McHenry MS, Nyandiko WM. The physical and psychological effects of HIV infection and its treatment on perinatally HIV-infected children. J Int AIDS Soc. (2015) 18:20258. doi: 10.7448/IAS.18.7.20258

57. Ungaro R, Taramasso L, Bruzzone B, Vicenti I, Galli L, Borghi V, et al. Prevalence of acquired resistance mutations in a large cohort of perinatally infected HIV-1 patients. Clin Microbiol Infect. (2019) 25:1443-6. doi: 10.1016/j.cmi.2019.07.004

58. Di Biagio A, Taramasso L, Gustinetti G, Burastero G, Giacomet V, La Rovere D, et al. Missed opportunities to prevent mother-to-child transmission of HIV in Italy. HIV Med. (2019) 20:330-6. doi: 10.1111/hiv.12728

Conflict of Interest: The authors declare that the research was conducted in the absence of any commercial or financial relationships that could be construed as a potential conflict of interest.

Copyright (C 2021 Chiappini, Larotonda, Lisi, Giacomet, Erba, Bernardi, Zangari, Di Biagio, Taramasso, Giaquinto, Rampon, Gabiano, Garazzino, Tagliabue, Esposito, Bruzzese, Badolato, Zanaboni, Cellini, Dedoni, Mazza, Pession, Giannini, Salvini, Dodi, Carloni, Cazzato, Tovo, de Martino and Galli. This is an open-access article distributed under the terms of the Creative Commons Attribution License (CC BY). The use, distribution or reproduction in other forums is permitted, provided the original author(s) and the copyright owner(s) are credited and that the original publication in this journal is cited, in accordance with accepted academic practice. No use, distribution or reproduction is permitted which does not comply with these terms. 